\title{
Non-Gaussian Bayesian retrieval of tropical upper tropospheric cloud ice and water vapour from Odin-SMR measurements
}

\author{
B. Rydberg ${ }^{1}$, P. Eriksson ${ }^{1}$, S. A. Buehler ${ }^{2}$, and D. P. Murtagh ${ }^{1}$ \\ ${ }^{1}$ Department of Radio and Space Science, Chalmers Univ. of Technology, Gothenburg, Sweden \\ ${ }^{2}$ Department of Space Science, Luleå Univ. of Technology, Luleå, Sweden
}

Received: 12 June 2009 - Published in Atmos. Meas. Tech. Discuss.: 13 July 2009

Revised: 2 October 2009 - Accepted: 28 June 2009 - Published: 28 October 2009

\begin{abstract}
Improved Odin-SMR retrievals of upper tropospheric water are presented. The new retrieval algorithm retrieves humidity and cloud ice mass simultaneously and takes into account of cloud inhomogeneities. Both these aspects are introduced for microwave limb sounding inversions for the first time. A Bayesian methodology is applied allowing for a formally correct treatment of non-unique retrieval problems involving non-Gaussian statistics. Cloud structure information from CloudSat is incorporated into the retrieval algorithm. This removes a major limitation of earlier inversion methods where uniform cloud layers were assumed and caused a systematic retrieval error. The core part of the retrieval technique is the generation of a database that must closely represent real conditions. Good agreement with Odin-SMR observations indicates that this requirement is met. The retrieval precision is determined to be about 5$17 \%$ RHi and $65 \%$ for humidity and cloud ice mass, respectively. For both quantities, the vertical resolution is about $5 \mathrm{~km}$ and the best retrieval performance is found between 11 and $15 \mathrm{~km}$. New data show a significantly improved agreement with CloudSat cloud ice mass retrievals, at the same time consistency with the Aura MLS humidity results is maintained. The basics of the approach presented can be applied for all passive cloud observations and should be of broad interest. The results can also be taken as a demonstration of the potential of down-looking sub-mm radiometry for global measurements of cloud ice properties.
\end{abstract}

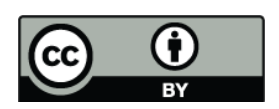

Correspondence to: B. Rydberg (bengt.rydberg@chalmers.se)

\section{Introduction}

Although upper tropospheric water vapour and cloud ice mass are keys to the prediction of future climate, knowledge of these parameters in the present atmosphere is limited (John and Soden, 2006). Satellite observation techniques are important for obtaining global and temporal information on atmospheric parameters. Traditional sensors, mainly operating in the visible and infrared region, are well suited for observing cloud top altitude, frequency of occurrence, and humidity for cloud free conditions, but they fail to penetrate clouds. This is necessary to get information of the total cloud ice mass and humidity in cloudy regions.

It has been suggested that cloud ice mass may be estimated by down-looking sub-millimetre radiometry (Evans and Stephens, 1995; Buehler et al., 2007), where the cloud penetration capability is good and the measured signal is generated by interaction with cloud particles carrying a dominant part of the cloud ice mass. Even though no such instrument exists in space, the two limb-sounding instruments, Odin-SMR (Murtagh et al., 2002) and Aura-MLS (Waters et al., 2006; Wu et al., 2006) operate in a similar manner and can determine upper tropospheric humidity and cloud ice mass simultaneously. Another interesting cloud sensor is the microwave Cloud Profiling Radar (CPR) on-board CloudSat (Stephens et al., 2002) which provides high quality cloud reflectivity measurements.

Odin-SMR is a passive sub-mm limb sounding radiometer operating near to $500 \mathrm{GHz}$. However, for low tangent point measurements the observation geometry can be regarded as slant angle down-looking, since strong water vapour absorption makes the lower part of the atmosphere opaque. For clear sky spectra brightness temperatures are approximately proportional to the relative humidity of the upper troposphere. Cloud ice interacts with sub-mm radiation

Published by Copernicus Publications on behalf of the European Geosciences Union. 
mainly through the scattering process, which acts to reduce the radiance measured. Simple retrieval schemes for cloud ice mass and humidity from Odin-SMR observations have previously been reported (Eriksson et al., 2007; Ekström et al., 2007).

A common problem for all passive observations is that the cloud properties are not homogeneous within the sampled volume. This was found to be a major retrieval uncertainty for Odin-SMR (Eriksson et al., 2008). The importance of inhomogeneity depends on the details of the observations, but it increases with the non-linearity of the relationship between cloud properties and measurement signal. If there is a nonlinear relationships between the amount of cloud ice mass and measurement signal, a homogeneous cloud field will have a greater impact on the measurement signal than an inhomogeneous cloud field with the same amount of ice mass within the volume sampled (Davis et al., 2007). A systematic retrieval error may be introduced if homogeneous clouds are assumed, which previously have been called beamfilling errors (Kummerow, 1998). The impact of cloud inhomogeneities must at least be characterised, or better, be incorporated into the retrieval process. This opens up for a very important indirect use of CloudSat data that can be used to improve on the accuracy of passive cloud measurements.

The objective of this article is to develop a retrieval algorithm that combines Odin-SMR measurement information with accurate a priori data from CloudSat and complementary data sources. This is to enable combined profile retrievals of tropical upper tropospheric humidity and ice water content where cloud inhomogeneity effects are handled as accurately as possible. The retrieval approach selected is Bayesian Monte Carlo integration (Evans et al., 2002), where the Bayes theorem is used to retrieve the conditional expected value of the atmospheric state for a given measurement. The Bayesian Monte Carlo integration retrieval algorithm is based on a pre-calculated retrieval database, consisting of atmospheric states and corresponding synthetic measurements. The atmospheric states in the retrieval database are created using a priori data and the retrieval algorithm effectively interpolates between the states that approximately match the measurement to be inverted.

The focus of the paper is to present how such a retrieval database can be constructed. A major consideration is that the atmospheric states in the retrieval database should be realistic and correctly distributed. A method for creating such a retrieval database for 1-D atmospheric states was presented in Rydberg et al. (2007). The methodology has been extended to create 3-D atmospheric states, as required to resolve cloud inhomogeneity effects. Realistic 3-D atmospheric states are generated by combining 2-D radar reflectivity measurements from the CPR on CloudSat, in situ measurements of cloud microphysics, weather data, and climatological data. A state-of-the-art radiative transfer simulator is used to simulate the instrumental measurement corresponding to the atmospheric states generated.
The novelty in this article is the practical demonstration on the use of CloudSat data to constrain retrievals of cloud ice water content profiles from microwave radiometry. In addition, the retrieval method is successfully applied on globally real data for the first time. It has previously only been used for case studies (Seo and Liu, 2005; McFarlane et al., 2002; Evans et al., 2005) and instrument concept studies (Zinner et al., 2008; Evans et al., 2002). The development is motivated by the need to improve the Odin-SMR retrievals, but the methodology should be of general interest since it can be used for any similar instrument.

\section{Non-Gaussian Bayesian retrieval methodology}

The goal of this article is to design an improved method for retrieving upper tropospheric ice water content and humidity profiles from Odin-SMR measurements. Three basic considerations are that the retrieval problem is non-unique and non-linear, and that upper tropospheric water exhibits nonGaussian statistics. Since a priori information to handle the non-uniqueness aspect exists, a Bayesian retrieval approach is suitable. Following the Bayes theorem, the conditional expected value of the state vector $(\hat{\boldsymbol{x}})$ is retrieved as

$\hat{x}=\int x P(x \mid y) d x=\int \frac{x P(y \mid x) P(x)}{P(y)} d x$,

where $\boldsymbol{y}$ is the measurement vector, $P(\boldsymbol{x} \mid \boldsymbol{y})$ is the conditional probability density function (PDF) of $\boldsymbol{x}$ given $\boldsymbol{y}, P(\boldsymbol{x})$ is the prior PDF of $\boldsymbol{x}, P(\boldsymbol{y} \mid \boldsymbol{x})$ is the conditional PDF of $\boldsymbol{y}$ given $\boldsymbol{x}$, and $P(y)$ is the prior PDF of the measurement. A direct application of Eq. (1) would require integration over the whole state space, which is a too demanding operation for most situations.

For non-linear and non-Gaussian inversion problems, such as the one faced here, several methods to solve Eq. (1) exist. Markov chain Monte Carlo (MCMC, Tamminen and Kyrölä, 2001), Bayesian Monte Carlo integration (BMCI, Evans et al., 2002), neural nets (NN, Jimenez et al., 2003), and non-linear regression (NLR) methods are some examples. MCMC provides a discrete representation of $P(x \mid y)$, which could be used to solve Eq. (1). The BMCI, NN, and NLR methods make use of a discrete representation of the state and measurement spaces through a retrieval database, in order to approximately solve Eq. (1). One fundamental difference between the approaches is that BMCI, NN, and NLR use a pre-calculated retrieval database, whereas MCMC requires new radiative transfer simulations for each inversion. For this reason, the MCMC method is too costly for this application.

A common requirement for applying BMCI, NN, and NLR is that a retrieval database matching reality with sufficient accuracy must be created. NN and NLR involve a second critical step where a mapping function is derived. This can potentially result in information being lost. The main drawback 
of BMCI is that the size of the retrieval database needed increases very rapidly with the dimensionality of the measurement space. The method requires that the synthetic measurements in the database fill the measurement space observed by the sensor with sufficient density. The database must hold at least a handful of cases that match any real measurement considering the error margins caused by noise and other observation uncertainties. For example, consider a hypothetical case where 100 cases are needed to fill the measurement space for each independent channel of a sensor. For $n$ independent channels, $100^{n}$ cases are then needed to fill the retrieval database.

The BMCI method has been selected due to its conceptual clarity, direct link to probability theory, and that the dimensionality of the measurement space of concern is relatively small. In the BMCI method, Eq. (1) is solved practically by transforming it into a Monte Carlo integration (Evans et al., 2002):

$\hat{\boldsymbol{x}} \approx \frac{\sum_{i} \boldsymbol{x}_{i} P\left(\boldsymbol{y} \mid \boldsymbol{x}_{\boldsymbol{i}}\right)}{\sum_{i} P\left(\boldsymbol{y} \mid \boldsymbol{x}_{\boldsymbol{i}}\right)}$,

where the summation is performed over states $\boldsymbol{x}_{\boldsymbol{i}}$ sampled from $P(\boldsymbol{x})$. In practice, the summation is performed over the states in the pre-calculated retrieval database and it is important that the atmospheric states in the retrieval database are sampled from $P(\boldsymbol{x})$. From Eq. (2) it is clear that the BMCI method works for all types of a priori distributions, although one must sample from the correct distribution. The retrieved state is a weighted average over all states in the database, where the weight $\left(P\left(\boldsymbol{y} \mid \boldsymbol{x}_{\boldsymbol{i}}\right)\right)$ of each state depends on the noise of the measurement and how closely the simulated measurement is to the actual measurements. If one assumes that the measurement noise is distributed in a Gaussian manner, which is often the case, then $P\left(\boldsymbol{y} \mid \boldsymbol{x}_{\boldsymbol{i}}\right)$ in Eq. (2) can be expressed as

$P\left(\boldsymbol{y} \mid \boldsymbol{x}_{i}\right) \sim \exp \left(-\frac{\left(\boldsymbol{y}-F\left(\boldsymbol{x}_{i}\right)\right)^{T} \mathbf{S}_{e}^{-1}\left(\mathbf{y}-F\left(\boldsymbol{x}_{\boldsymbol{i}}\right)\right)}{2}\right)$,

where $F\left(\boldsymbol{x}_{\boldsymbol{i}}\right)$ is the simulated measurement vector for state $\boldsymbol{x}_{i}$ and $\mathbf{S}_{e}$ is the measurement noise covariance matrix. The error estimate, the conditional expected covariance matrix $\hat{\mathbf{S}}$, is obtained by

$$
\begin{aligned}
\hat{\mathbf{S}} & =\int(\boldsymbol{x}-\hat{\boldsymbol{x}})(\boldsymbol{x}-\hat{\boldsymbol{x}})^{T} P(\boldsymbol{x} \mid \boldsymbol{y}) \boldsymbol{d} \boldsymbol{x} \\
& \approx \frac{\sum_{i}\left(\boldsymbol{x}_{\boldsymbol{i}}-\hat{\boldsymbol{x}}\right)\left(\boldsymbol{x}_{\boldsymbol{i}}-\hat{\boldsymbol{x}}\right)^{T} P\left(\boldsymbol{y} \mid \boldsymbol{x}_{\boldsymbol{i}}\right)}{\sum_{i} P\left(\boldsymbol{y} \mid \boldsymbol{x}_{\boldsymbol{i}}\right)} .
\end{aligned}
$$

Hence, once the retrieval database is calculated, one can inexpensively invert measurements by the use of Eq. (2) and Eq. (4), since the equations do not involve any heavy calculations.
The sensitivity of the retrieval to the true state, $\mathbf{A}=\partial \hat{\boldsymbol{x}} / \partial \boldsymbol{x}$, is a matrix that contains information on the response and vertical resolution of the measurements, but is not a product that the selected retrieval method provides directly. However, by assuming the retrievals to be close to linear, an average estimate of $\mathbf{A}$ can be obtained indirectly from the retrieval database and Eq. (3.12) in Rodgers (2000):

$\hat{\boldsymbol{x}}=\boldsymbol{x}_{a}+\mathbf{A}\left(\boldsymbol{x}-\boldsymbol{x}_{a}\right)$,

where $\boldsymbol{x}_{\boldsymbol{a}}$ is the mean state of $\boldsymbol{x}$ and measurement noise is ignored. With some rearrangements of Eq. (5) one obtains

$\mathbf{A}=\left(\left(\Delta \mathbf{X} \Delta \mathbf{X}^{T}\right)^{-1} \Delta \mathbf{X} \Delta \hat{\mathbf{X}}^{T}\right)^{T}$,

where

$\Delta \hat{\mathbf{X}}=\left[\hat{\boldsymbol{x}}_{1}-\boldsymbol{x}_{\boldsymbol{a}}, \hat{\boldsymbol{x}}_{2}-\boldsymbol{x}_{\boldsymbol{a}}, \ldots, \hat{\boldsymbol{x}}_{n}-\boldsymbol{x}_{\boldsymbol{a}}\right]$

and

$\Delta \mathbf{X}=\left[x_{1}-x_{a}, x_{2}-x_{a}, \ldots, x_{n}-x_{a}\right]$.

The sum of the diagonal of $\mathbf{A}$ gives the degrees of freedom for the signal $d_{s}$ (Rodgers, 2000),

$d_{s}=\operatorname{tr}(\mathbf{A})$,

which can be interpreted as the number of independent quantities that we can extract from the observation system.

As already mentioned, the crucial part of inverting measurements using the BMCI method is to create a retrieval database consisting of atmospheric states $\left(\boldsymbol{x}_{\boldsymbol{i}}\right)$ and the corresponding synthetic measurement $\left(\boldsymbol{y}_{\boldsymbol{i}}\right)$ for each state. The retrieval methodology can be summarised as (Fig. 1):

- An atmospheric database consisting of 3-D atmospheric states is created based on a priori information. The atmospheric states in the database should be distributed according to $\mathrm{P}(\boldsymbol{x})$, also covering extreme cases, and include all atmospheric and sensor parameters that affect the measurements. To include extreme states is important as the retrieval algorithm (Eqs. 2-4) can not extrapolate. This, as the retrieved state is a weighted average of all states in the database. Thus in practice, the number of extreme states in the database should be larger, rather than smaller, than in reality.

- The atmospheric states together with sensor characteristics are fed into a radiative transfer model to simulate a synthetic measurement for each state.

- Real measurements, together with the generated retrieval database are given to the retrieval algorithm. This algorithm integrates over the states in the database according to Bayes theorem to provide an estimate of the state. 


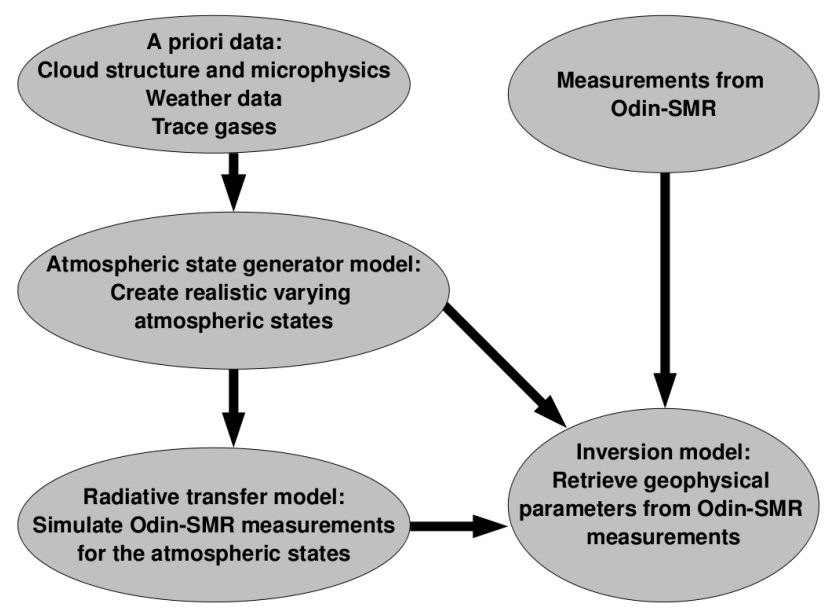

Fig. 1. Block diagram describing the retrieval methodology.

\section{Observations and a priori data}

This section describes the data involved in the study. The aim of the study is to retrieve tropical upper tropospheric water from Odin-SMR measurements by combining measurement information with a priori data.

\subsection{Odin-SMR observations}

The Odin satellite was launched in February 2001 into a $600 \mathrm{~km}$ quasi-polar sun-synchronous orbit, with ascending node around 18:00 h. The payload includes the first space-borne sensor for atmospheric sub-mm observations, Odin-SMR. This limb sounding instrument measures thermal emission at frequencies around $500 \mathrm{GHz}$. The atmospheric signal is recorded through a $1.1 \mathrm{~m}$ telescope, single-sideband heterodyne receivers, and two auto-correlation spectrometers with $800 \mathrm{MHz}$ bandwidth. Further information can be found in Murtagh et al. (2002) and Ekström et al. (2007).

Only measurements (level $1 \mathrm{~b}$, v6) collected inside $\pm 30^{\circ}$ in latitude are considered here. Also, only low tangent point measurements are included, as this greatly reduces the complexity of the observation geometry. For measured spectra with tangent altitudes below $\sim 9 \mathrm{~km}$, the atmosphere around the tangent point acts as a blackbody background, due to strong water vapour absorption. The observation geometry can be seen as a slant down-looking geometry, where the sampling volume inside the troposphere is a tilted cylinder with approximate dimensions of $2 \times 2 \times 45 \mathrm{~km}^{3}$. Relationships between atmospheric variables and observed brightness temperatures, and other details of the measurements, are treated in detail by Ekström et al. (2007) and Eriksson et al. (2007).

\subsection{Cloud, weather, and atmospheric a priori data}

The a priori data described below are used as input to create the retrieval database.

\subsubsection{CloudSat}

CloudSat is a satellite designed to measure the vertical structure of clouds from space (Stephens et al., 2002). The satellite has a 13:40 ascending node, sun-synchronous orbit at $705 \mathrm{~km}$ altitude. CloudSat carries a $94 \mathrm{GHz}, 0.16^{\circ}$ off-nadirlooking Cloud Profiling Radar (CPR) which measures the power back-scattered by clouds as a function of distance from the radar. The standard data product consists of 125 vertical bins that are $240 \mathrm{~m}$ thick, while the vertical resolution of the radar is approximately $500 \mathrm{~m}$. Each profile is generated over a $160 \mathrm{~ms}$ integration time with a $6 \mathrm{~dB}$ footprint resolution of approximately $1.3 \mathrm{~km}$ across-track and $1.7 \mathrm{~km}$ along track. The minimum detectable equivalent radar reflectivity is approximately $-30 \mathrm{dBZ}$ and the dynamic range is $70 \mathrm{dBZ}$. This study uses radar reflectivities from the 2B-GEOPROF product version 011 provided by the CloudSat Data Processing Center.

\subsubsection{Cloud ice microphysics}

Cloud ice microphysics refers here to ice particle sizes and shapes. A cloud ice particle size distribution parameterisation derived by McFarquhar and Heymsfield (1997) is used to describe the particles size variation. This parameterisation is based on tropical in situ measurements. Particle shape assumptions are discussed in Sect. 4.1.2.

\subsubsection{Weather and atmospheric data}

Temperature, humidity, and ozone data are taken from the ECMWF-AUX product, version 008, provided by the CloudSat Data Processing Center. Atmospheric gas concentrations of $\mathrm{O}_{2}, \mathrm{~N}_{2}, \mathrm{ClO}$, and $\mathrm{HNO}_{3}$ are taken from a tropical climatology (Fascod), and $\mathrm{N}_{2} \mathrm{O}$ from an Odin-SMR derived climatology.

\section{Construction of retrieval database}

\subsection{Construction of atmospheric states}

The generation of atmospheric states can be summarised as (Fig. 2):

- A 2-dimensional (2-D) cloud radar reflectivity measurement is fed into a Fourier transform algorithm that generates a stochastic 3-D radar measurement field (Venema et al., 2006).

- The 3-D radar measurement field is combined with temperature data and a particle size distribution parameterisation, and fed into a cloud generator model. The output 
of the cloud generator model is a 3-D field of ice water content and underlying particle size distributions, with conserved radar backscattering properties.

- The 3-D cloud field, together with weather data and climatological information of trace gases are passed on to an atmospheric scene generator model. This model generates 3-D gas and temperature fields, where fine scale structure are added to the fields to account for variability not resolved by the data sources.

\subsubsection{Cloud structures}

Cloud states are generated in a series of steps, where the first step deals with obtaining 3-D cloud structures. Detailed input data are required to obtain realistic 3-D cloud structures. Possible data sources are cloud resolving models, radars, and in situ measurements. In situ measurements exist only for a few clouds and are therefore not appropriate for the use here. The advantage of using radar measurements as input, as compared to using cloud resolving model data, is that correct statistical properties of cloud structures are obtained automatically. Therefore, using radar cloud structure measurements as input was considered most suitable.

The CPR on-board CloudSat collects cloud structure measurements throughout the tropical region, and using CloudSat instead of data from tropical ground based radars gives a statistical advantage. The CPR on-board CloudSat provides high resolution 2-D cloud reflectivity measurements. A transformation to 3-D is achieved by inputting such 2-D measurements into a stochastic iterative amplitude adjusted Fourier transform algorithm (Venema et al., 2006). This algorithm generates surrogate 3-D radar measurement fields with the same amplitude distribution and power spectrum as the original fields. The CloudSat data were inputted as orbit sections having a $4^{\circ}$ latitudinal extension and full resolution ( $\sim 200 \mathrm{~m}$ in vertical $\times 2 \mathrm{~km}$ in latitude), that yield 3-D fields covering $4^{\circ}$ in both latitude and longitude with the same spatial resolution as the input.

\subsubsection{Cloud microphysics}

The concept is to create 3-D cloud fields that conserve the surrogate 3-D radar reflectivities. Two assumptions are made regarding microphysical properties:

- Cloud ice particle size distribution (PSD) variations seem to be complex in nature. PSDs vary both within clouds and from cloud to cloud. Ideally, the PSDs in the cloud states in the database should follow this natural variability. If this was the case, the retrieval uncertainty associated with PSD variability would have been incorporated in the retrieval algorithm. However, no PSD parameterisation exists that can describe the full true ice cloud variability. A method to include variations in the mean particle size and width of the PSD

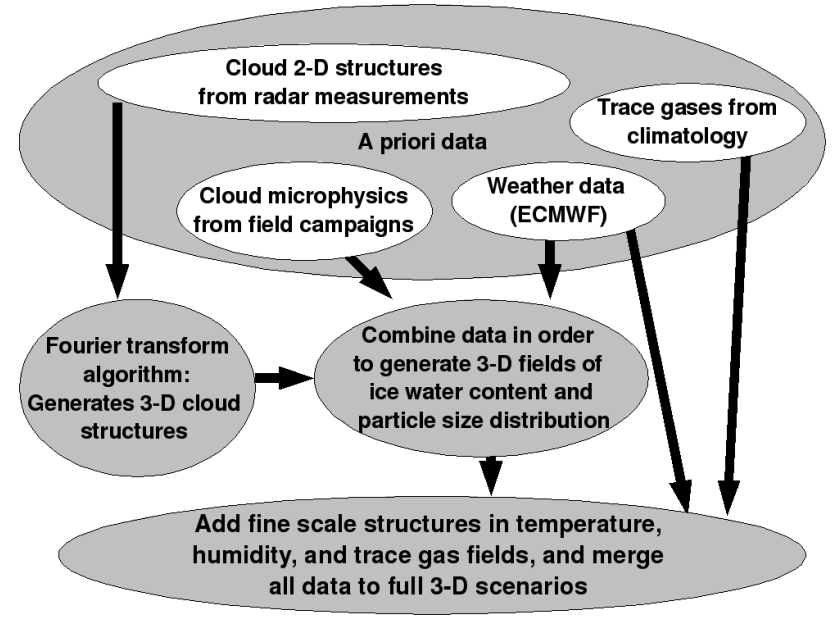

Fig. 2. Block diagram describing how atmospheric states are realised.

is presented in Rydberg et al. (2007). That method was basically applied in order to predict the retrieval performance of a dedicated cloud instrument, capable of measuring some PSD parameters. However, OdinSMR provides no mean in estimating PSD parameters. Thus, applying a method to generate variations of PSD parameters would basically only effect the retrieval uncertainty. An alternative approach would be to apply a fixed well defined PSD parameterisation. The drawback with this approach is that retrieval uncertainties must be handled separately. On the other hand, there are two considerable advantages. As the degrees of freedom of the cloud states in this approach is smaller, the number of states in the database can be smaller. Additionally, it is more straight forward to directly compare to results from similar instruments. The PSD parameterisation derived by McFarquhar and Heymsfield (1997) (hereafter MH97) is assumed to be the best representation of the mean PSD in the tropical region. The PSD, $n(D)$, is described by a non linear function of IWC $(w)$ and temperature $(T)$,

$n(D)=f(D, w, T)$.

where $D$ is the particle diameter. It should be clear that local PSDs may deviate significantly from MH97. However, no deviations from MH97 are included in the database states, as sufficient information of how much local PSDs may deviate from MH97 is lacking. This has the consequence that the full natural variation of PSDs is not covered by the database states, but, as long as MH97 is a fair representation of the mean PSD no large systematic retrieval errors are introduced and the associated random retrieval uncertainty can be characterised separately (Sect. 5.4). 
- Natural occurring cloud ice particles can have very complex shapes. The crucial aspect here is that average scattering properties of particle ensembles are represented in an appropriate manner with respect to the observations. The Odin-SMR receivers have a $\pm 45^{\circ}$ linearly polarised response, meaning that a combination of the first and third Stokes components are measured. For Odin-SMR observations of most atmospheric states the third Stokes component is close to zero. Scattering by non-spherical particles can give rise to differences in the vertical and horizontal component of the radiation, but the first Stokes component (total intensity) is less influenced by realistically varying particle shapes (Eriksson et al., 2007). In (Evans et al, 1998) (e.g. Fig. 8) nadir viewing sensitivity to 8 different particle shapes, including spheres, at $500 \mathrm{GHz}$ is shown. It is shown that the induced intensity depression depends on assumed particle shape for a given mass equivalent sphere PSD. The induced depression by spheres tends to be in the centre of the depression produced by more complex shaped particles. These particles produced depressions that are within $\pm 50 \%$ as that for spheres. By considering that a cloud consists of a variety of particle shapes, we assume that mass equivalent spheres closely describes the averaged scattering properties of particle ensembles in realistic clouds. This enables the use of Mie theory for calculating the scattering properties of ice particles. However, for instruments measuring only the vertical, or horizontal, components of the radiation effects of non-spherical particles should be considered.

Equivalent radar reflectivity, $Z_{e}$, is related to the cloud microphysics according to

$Z_{e}=\frac{\lambda^{4}}{4 \pi^{4}\left|K_{w}\right|^{2}} \int_{0}^{\infty} q_{b}(D, T) f(D, w, T) d D$,

where $\lambda$ is the wavelength, $K_{w}$ the dielectric factor of water, and $q_{b}(D, T)$ is the backscattering cross section. The radar backscattering is calculated by Mie theory.

The general situation is that a measured $Z_{e}$, at a known $T$, can be explained by a range of IWC values. However, as MH97 is assumed to describe the PSD, radar reflectivity has an unambiguous relation to IWC and $T$ within relevant variable ranges. Hence, IWC can be derived for given $Z_{e}$ and $T$ by, for example, a pre-calculated look-up table. When the IWC matching $Z_{e}$ and $T$ is determined, the PSD is obtained from Eq. (10). This procedure ensures that the radar reflectivity is conserved for the generated microphysical fields.

\subsubsection{Weather and atmospheric structures}

The 3-D fields of these variables are generated in a series of steps. As a starting point weather data (temperature, humidity, and pressure) and ozone, originating from ECMWF, are obtained from CloudSat auxiliary data archive. The ECMWF data are 2-D cross-sections (latitude and pressure) and initial 3 -D fields are created by assuming no longitudinal variation. The viewing direction of Odin-SMR in the tropical region is approximately north to south, or reversed, and the treatment of the longitude dimension is less critical. The volume mixing ratio of gas species beside ozone are set to tropical climatological values.

To account for weather variations on scales not resolved by ECMWF and for natural variations of trace gas concentrations, perturbations are made in the 3-D fields. A stochastic method adding 1-D structures is described in Rydberg et al. (2007), and the modification of 3-D fields is done following the same basic approach. The method effectively adds a field with a zero mean and desired standard deviations and spatial correlations to the original field. Standard deviations are set to values that are approximately determined by the uncertainty of ECMWF data ( $1 \mathrm{~K}$ for temperature, $20 \%$ for ozone, and $10 \%$ for water vapour). The variation of $\mathrm{ClO}$ and $\mathrm{HNO}_{3}$ was set to $40 \%$ for all altitudes while $\mathrm{N}_{2} \mathrm{O}$ was only perturbed above $200 \mathrm{hPa}$ with $30 \%$. Assumed values of interlevel correlation lengths are based on educated guesses. The vertical exponential correlation length of all fields is set to $1 \mathrm{~km}$ at the surface level, and to increase with altitude up to the upper troposphere. At the upper troposphere and above $3 \mathrm{~km}$ is assumed. The latitudinal and longitudinal correlation lengths are throughout all states set to $0.5^{\circ}$.

It was found that ECMWF underestimates the variability of upper tropospheric humidity when compared to values found by Ekström et al. (2007). Since it is important that the database covers extreme states, the humidity fields were modified by scaling each 2-D cross-section by a factor randomly selected in the range $[0.6,1.4]$ before further processing. A scaling factor symmetric around 1 was chosen to obtain a distribution of upper tropospheric humidity more resembling the results of Ekström et al. (2007), at the same time as the ensemble mean humidity is conserved. Furthermore, generated 3-D perturbed humidity fields inside clouds is modified by assuming that the RHi is close to saturation following Rydberg et al. (2007).

\subsection{Radiative transfer simulations}

The second part of the generation of the retrieval database consists of simulating synthetic measurements for each atmospheric state. The simulations were performed using version 1.1 of the Atmospheric Radiative Transfer Simulator (ARTS). This is a development of the first version, ARTS1 (Buehler et al., 2005), where two scattering modules, a discrete ordinate iterative method (Emde et al., 2004) and a reverse Monte Carlo algorithm (Davis et al., 2005) have been implemented to solve the polarised radiative transfer equation. In ARTS the polarisation state is expressed by the Stokes formalism, the geoid and surface can have arbitrary shape, and atmospheric fields can have variations in three dimensions. 


\subsubsection{Instrument response simulations}

Simulations of Odin-SMR observations were performed for each 3-D atmospheric state generated. For cases including clouds, the cloud influence on the radiance was simulated using the Monte Carlo module of ARTS, whereas radiances for cases lacking clouds were simulated in the ordinary clear sky mode of ARTS. In all cases the 3-D variability of the atmosphere is fully considered in the radiance simulations.

The selected Odin-SMR frequency bands are centred around 501.2 and $544.4 \mathrm{GHz}$, and a single frequency (centre frequency) is used to represent each band. Odin-SMR is a single sideband heterodyne receiver, but only the primary band is simulated. This has very little influence on simulated radiances for the observation geometry of concern, as discussed in Eriksson et al. (2007). Simulations were performed for the total intensity of the radiation, which for normal conditions closely approximates the Odin-SMR receiver of $\pm 45^{\circ}$ linearly polarised response (Sect. 4.1.2).

The strengths of molecular transitions and other spectroscopic data are mainly taken from the operational Odin-SMR retrievals of stratospheric gas species (Urban et al., 2005). Of special concern for tropospheric observations is that nitrogen absorption follows Liebe et al. (1993) and that this absorption is scaled with a factor of 1.34 as suggested by Boissoles et al. (2003). New data were selected for some important water vapour variables. The pressure broadening width coefficients for the $556.9 \mathrm{GHz}$ water vapour transition are here taken from Golubiatnikov et al. (2008), and the water vapour "continuum" parameterisation follows Podobedov et al. (2008).

The antenna pattern of Odin-SMR yields an upper tropospheric resolution (full width at half maximum) of $\sim 2 \mathrm{~km} \times 2 \mathrm{~km}$ in vertical and across-track dimensions, where the across-track resolution is comparable (and aligned) to the one of CloudSat, and hence to the horizontal resolution of atmospheric states generated. The azimuthal variation of the antenna response can thus be neglected. However, the azimuthal/longitude variation of the atmospheric scenes have an impact for cloudy scenes as scattering out of the observation plane then occurs. Accordingly, an azimuthally integrated antenna pattern was applied, where pencil beam simulations were performed for tangent altitudes with a vertical spacing of $250 \mathrm{~m}$. In cloudy cases, where Monte Carlo simulations are used, each pencil beam simulation was run to a precision of $3 \mathrm{~K}$. This yields, after the antenna weighting, a total precision better than $1 \mathrm{~K}$.

The Monte Carlo module of ARTS can not handle refraction, and therefore, a simple correction scheme was applied. Clear sky simulations, including and excluding, refractive effects were performed. It was found that clear sky simulations, excluding refractive effects, could reproduce the level of radiance of simulations including refractive effects, if the tangent points were moved $500 \mathrm{~m}$ closer to the surface. Therefore, a $500 \mathrm{~m}$ offset in tangent point is used to compensate for refractive effects that are not included. The remaining calculation error has a marginal impact on final results.

\subsection{Representation of atmospheric states}

The atmospheric states in the retrieval database must be 3-D in order to include cloud inhomogeneity effects in simulated measurements, but it is not feasible to retrieve any atmospheric 3-D structures. First of all, Odin-SMR does not provide a continuous coverage horizontally. In addition, the measurements are inverted individually. There is, accordingly, no information on horizontal structures in the measurements and the only reasonable aim is to retrieve some average for the horizontal area probed. On the other hand, vertical information is present through differences in absorption at 501 and $544 \mathrm{GHz}$, primarily through pressure broadening of a very strong water vapour transition at $556.9 \mathrm{GHz}$. This applies to both humidity (Ekström et al., 2007) and cloud scattering (Eriksson et al., 2007), and profile retrievals of both RHi and IWC are attempted. This in contrast to earlier OdinSMR cloud retrievals where only partial column values have been retrieved.

The database state vectors for use in Eq. (2) shall thus hold vertical profiles of RHi and IWC. That is, a 1-D representation of the humidity and cloud ice fields. The best 1-D representation of the 3-D states should consider the spatial weighting by the antenna pattern. Hence, 1-D profiles of IWC and $\mathrm{RHi}$, for each state, are obtained by first extracting values of these parameters along each pencil beam where the radiative transfer simulations were performed. These profiles are weighted according to the Odin-SMR antenna pattern (analogously to how radiances are weighted).

This means that each case in the retrieval database consists of a 3-D atmospheric state, a synthetic instrument measurement vector, and a 1-D representation of the 3-D state. The 1-D state vectors and the synthetic instrument vectors are the input to the retrieval algorithm. The retrieval database consists of a total of $\sim 400000$ cases. This size includes cases covering measurements from 0 to $9 \mathrm{~km}$ in tangent altitude. Hence, not all of these cases can effectively be used as input for the inversion of a measurement from a given tangent point, and the effective database size for individual cases is $\sim 30000$ cases. This can be compared to a required size which is on the order of $100^{2}=10000$, following the rough estimate in Sect. 2 whose assumptions approximately applies to Odin-SMR.

\section{Results}

Basic considerations for the retrievals are treated in Ekström et al. (2007) and Eriksson et al. (2007), and the details are not repeated here. One conclusion of those studies is that it is sufficient to consider two frequency bands to preserve 


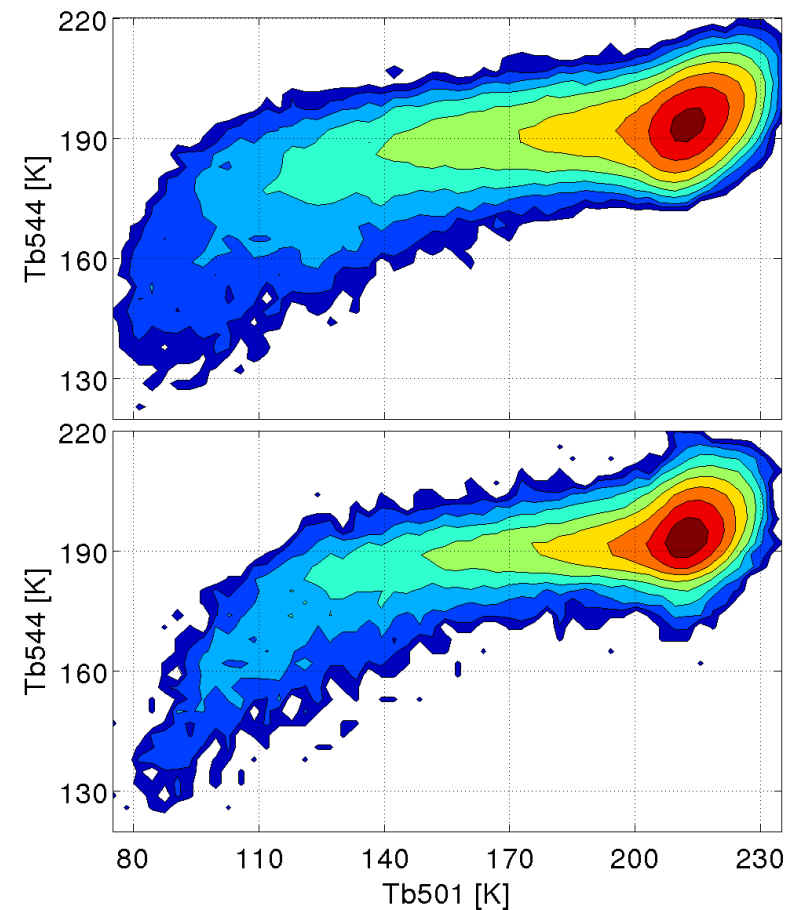

Normalised radiance frequency distribution $\left[1 /(3 \mathrm{~K})^{2}\right]$

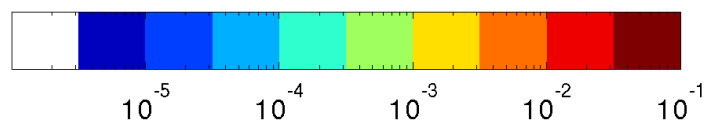

Fig. 3. Upper panel: radiance distribution of simulated Odin-SMR measurements, with measurement noise added. Lower panel: radiance distribution of real Odin-SMR measurements.

the information content for the retrievals of concern and only two frequencies are therefore considered here. The two frequencies are 501.2 and $544.4 \mathrm{GHz}$.

\subsection{Radiance comparison}

A basic test is that the distribution of generated radiances resembles that of the measured radiances. If the radiance distributions for the database and the real Odin measurements differ significantly, one or several steps of the simulations have been handled incorrectly and the database can not be applied for retrievals. This retrieval uses data from only two frequency channels and radiances can be displayed as 2-D distributions (501 vs. $544 \mathrm{GHz}$, Fig. 3). The upper right region of the figure panels corresponds to states which contain no or very thin clouds, while the lower left region corresponds to states that are greatly influenced by cloud scattering.

The agreement between the two distributions in Fig. 3 must be judged as highly satisfactorily. The simulated distribution is in general somewhat broader, which is an advantage compared to an opposite tendency as discussed in
Sect. 2. This is particularly true for the part of the distribution corresponding to a strong impact of clouds and a possible contributing factor to the broader simulated distribution is diurnal variations in tropical deep convection. Such diurnal variations are well known (Liu and Zipser, 2008) and as CloudSat performs its measurements at local times around 01:40 and 13:40 while Odin-SMR observes around 06:15 and 18:15 some differences in obtained brightness temperatures are expected. Diurnal differences in CloudSat and Odin-SMR measurements are being examined and will be presented separately.

The measurements show a higher variation in the $544 \mathrm{GHz}$ channel for brightness temperatures around $210 \mathrm{~K}$. This can be the result of an under-representation of very dry and very humid situations at altitudes around $14 \mathrm{~km}$, but is more likely an effect of that simulated noise does not totally capture the behaviour of the more unstable performance of this receiver chain for level $1 \mathrm{~b}$ v6 data (Ekström et al., 2007). The otherwise good agreement for the clear sky domain of the radiance distributions (upper right corner) indicates that the imposed variation for temperature and humidity in the database mimics real conditions satisfactorily.

The good agreement between the distributions in Fig. 3 is not proof that everything is handled correctly. There could be counteracting issues and incorrect values for less influential parameters can not be resolved in this manner. However, there is no obvious way to strictly validate the retrieval database. For example, if any better data were available they should be included in the retrieval database.

\subsection{Retrieval setup and characterisation}

The final retrieval setup was determined by inverting simulated measurements. The test retrievals were performed by dividing the database into a smaller retrieval database and a test part, each consisting of $\sim 200000$ cases.

Obvious elements of the measurement vector $\boldsymbol{y}$ are the two measured brightness temperatures, at 501 and $544 \mathrm{GHz}$. The standard deviation for the noise at $501 \mathrm{GHz}$ was set to $2 \mathrm{~K}$, while for $544 \mathrm{GHz}$ it was assumed to vary where $3.5 / 2.5 \mathrm{~K}$ were selected for shortest/longest integration time (Ekström et al., 2007). The geometric tangent altitude, $z_{t}$, of OdinSMR spectra has been estimated to have an uncertainty following a Gaussian distribution with a standard deviation of about $200 \mathrm{~m}$. This knowledge was treated as measurement information and $z_{t}$ was included in $\boldsymbol{y}$. The alternative would be to divide the data into ranges of tangent altitudes and split up the retrieval database in the same manner. However, the inclusion of $z_{t}$ in $\boldsymbol{y}$ is directly in line with the selected Bayesian retrieval methodology by using existing information in an optimal manner and is thus to prefer.

Odin-SMR data do not provide independent information on humidity and temperature. Retrieval tests showed also some improvements for the humidity retrieval when external temperature information was added to $(\boldsymbol{y})$ and this option 


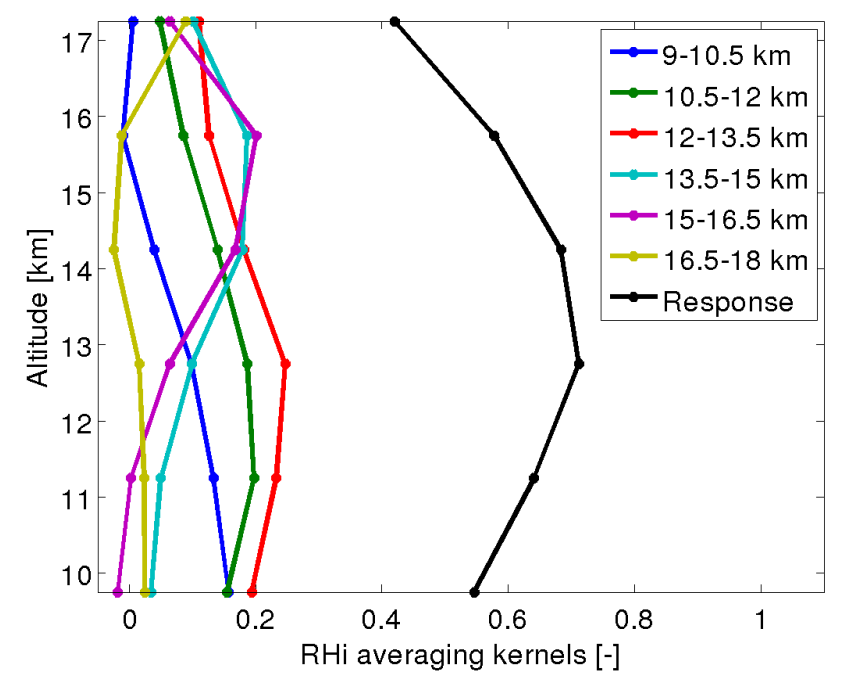

Fig. 4. Averaging kernels (rows of $\mathbf{A}$ ) and total measurement response (the sum of each kernel) for relative humidity.

was selected for the final retrieval setup. A single temperature was chosen in order to keep the measurement vector as short as possible. The temperature at $140 \mathrm{hPa}$ was selected as this level is approximately in between the altitudes where the two channels have their maximum sensitivity. The temperature information is taken directly from ECMWF when inverting real Odin-SMR measurements. The standard deviation for the uncertainty for this piece of information was set to $1 \mathrm{~K}$. All measurement uncertainties are assumed to be totally uncorrelated and $\mathbf{S}_{\mathbf{e}}$ in Eq. (3) is a diagonal matrix.

The state vector holds 1-D antenna-weighted IWC and humidity profiles (Sect. 4.3). It was found that a grid spacing of $1.5 \mathrm{~km}$ is appropriate and a state vector covering altitudes from 9 to $18 \mathrm{~km}$ with a spacing of $1.5 \mathrm{~km}$ is used in all retrievals presented. For both RHi and IWC, the values at each grid point represent the average of the quantity inside the layer (the first layer is from $9-10.5 \mathrm{~km}$ and so on).

Figure 4 shows an estimate of the ensemble mean averaging RHi kernels, which were obtained as discussed in Sect. 2. The greatest response $(\sim 0.7)$ is found for the three layers covering $10.5-15 \mathrm{~km}$. The direct sensitivity of the measurements to water vapour outside this altitude range is much lower, but the retrievals do not exhibit a corresponding decline in the response. This is as a consequence of applying a Bayesian approach. The retrievals use correlations found in the a priori data to obtain information in regions where the measured radiances in themselves have little, or even no, sensitivity. Thus, the quality of such retrievals are very dependent on whether the correlations assumed actually exist.

Figure 5 shows an estimate of the ensemble mean averaging kernels for IWC. The kernels were determined for the logarithm of the IWC, in order to stabilise the least square fitting procedure. All IWC values below $0.1 \mathrm{mg} \mathrm{m}^{-3}$, including

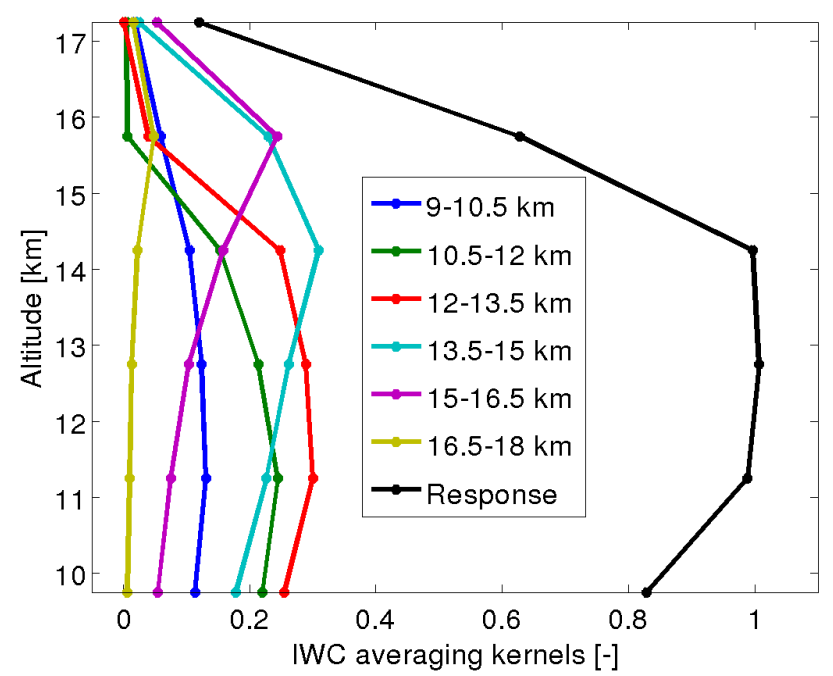

Fig. 5. Averaging kernels (rows of $\mathbf{A}$ ) and total measurement response (the sum of each kernel) for the logarithm of ice water content.

zero values that are below the detection limit of Odin-SMR (Sect. 5.4), were given small random numbers in the range $0.001-0.1 \mathrm{mg} \mathrm{m}^{-3}$, in order to be able to work with a $\log$ scale. Different ranges were tested but the results remained stable. Giving these small values a fixed number instead might intuitively sounds better. However, that would lead to an overestimation of the response, as it would look like that the retrievals can exactly reproduce these values. The greatest response $(\sim 1.0)$ is found for $10.5-15 \mathrm{~km}$, as for humidity, and drops to $\sim 0.65$ and 0.85 for the two surrounding layers. Below $16 \mathrm{~km}$, the response is higher for IWC compared to RHi. This as the measured brightness temperatures are much stronger affected by clouds than by humidity. The reason for the low response in the highest layer is that there exists relatively little cloud ice there.

The trace of the estimated ensemble mean averaging kernels matrix gives information on how many independent pieces of information that can be extracted from the measurements. This number is 2.3. This is consistent to the fact that the main information is coming from the two, more or less independent, Odin-SMR channels considered. For weak cloud conditions these two pieces of information approximately corresponds to the RHi in the lower and upper part of the tropical uppermost troposphere, and to the IWC in the same layers for cases where the measured intensity is influenced by clouds. For cloudy cases, the retrieved RHi is to a large extent determined by the statistics of a priori data.

Another way to look at the information content is to estimate the vertical resolution, which is in the order of $5 \mathrm{~km}$ (full width at half maximum of the averaging kernels) for both RHi and IWC. This resolution is rather coarse compared to the selected grid spacing of $1.5 \mathrm{~km}$. However, retrieved 


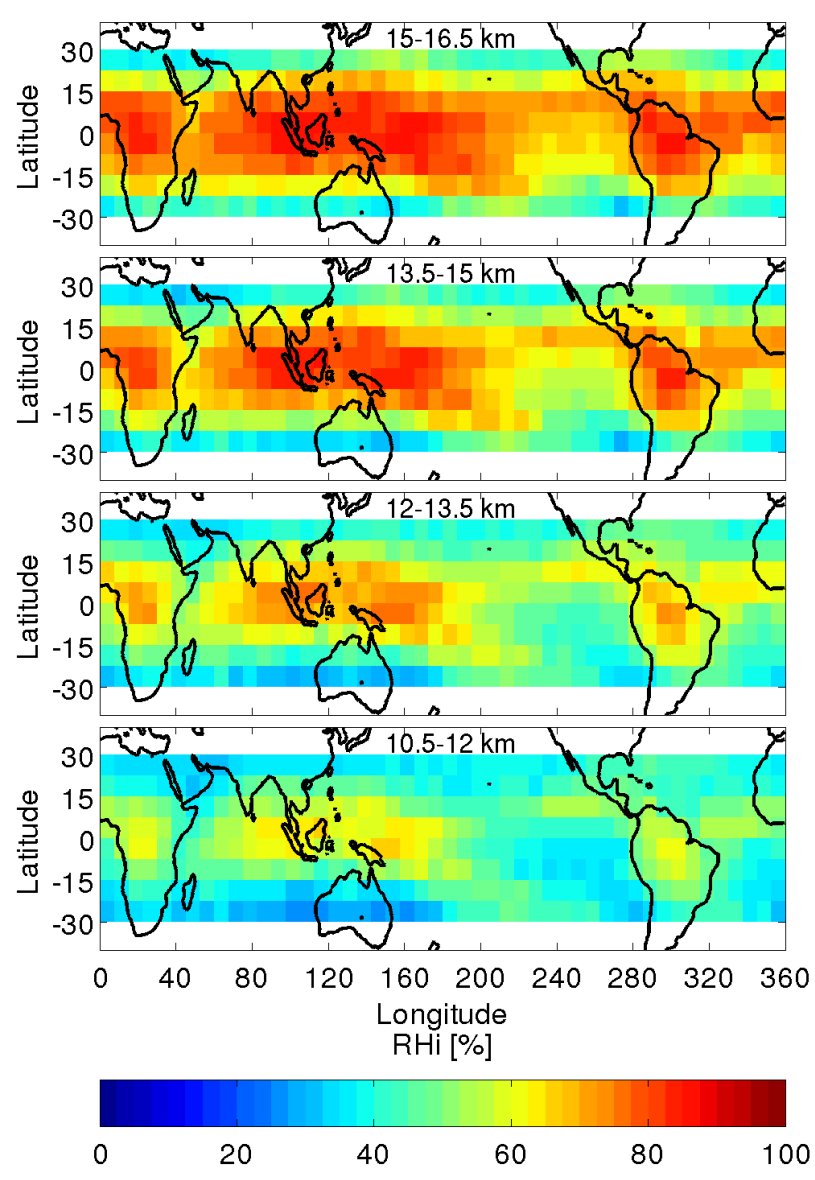

Fig. 6. Odin-SMR multi year means of retrieved relative humidity.

profiles can be seen as moving averages in the vertical dimension, where the averaging kernels describe the weighting. Accordingly, the retrievals at the different levels carry to some extent independent information and results for the four layers covering the altitude region from 10.5 to $16.5 \mathrm{~km}$ are displayed below. The response is above 0.6 for both RHi and IWC throughout this altitude region.

\subsection{Retrieved relative humidity}

Odin-SMR RHi retrievals are presented as multi year mean results for four vertical layers in Fig. 6. The geographical patterns of RHi are in general agreement with AURA-MLS data (see e.g. Ekström et al., 2007). Regions of high RHi are found over Central Africa, Central and South America and over the maritime continent. These are regions associated with strong convection. The regions of high RHi become broader with increasing altitude. This follows from the fact that the humidity is more controlled by zonal mixing at the highest altitudes, while local convection is the dominating factor at lower altitudes. Additionally, at higher altitudes the average RHi is closer to saturation.
The retrieval database does not include any geographical information and the a priori fields corresponding to Fig. 6 are completely flat. That is, all horizontal structures in retrieved results come from the measurements. In addition, the fact that the geographical patterns of mean RHi differ between the vertical layers indicates that vertical information has been extracted from the measurements.

The retrieval accuracy is examined in Fig. 7. The figure is based on the retrieval simulations described in Sect. 5.2. The retrieval works best for the two vertical layers between 12 to $15 \mathrm{~km}$. The retrieved RHi compare in general well to the true RHi. The retrieval accuracy (difference between mean retrieved RHi for each interval and the true RHi) is within $10 \%$ for RHi below $90 \%$. The effective noise is higher for the $544 \mathrm{GHz}$ band, which is reflected by a somewhat poorer precision for the two higher layers. In addition, the measurement sensitivity to water vapour in the uppermost layer is relatively small, compared to the other layers. The systematic retrieval error has a consistent pattern. The retrieved mean values are lower than the true RHi for high RHis and higher than the true RHi for low RHis, where the brake point is found around $70 \%$ RHi. This is an effect of that the measurements do not provide complete information and the BMCI method favours more likely states. The influence of the a priori data is especially high for RHi above $90 \%$ RHi. This is due to the effects of that saturation in the measurement signal occurs (Ekström et al., 2007), and the measurement noise is approximately as high as the variation between the signal at 70 and $150 \%$ RHi. Thus, retrievals are here greatly effected by a priori data. As individual retrieved values are the most likelihood solution, the only way to reduce systematic retrieval errors would be to reduce the measurement noise, dominated by calibration errors. It is to date not known why there are such high random calibration errors. A simple correction for geographical averaged retrievals, taking into account the retrieval biases in Fig. 7, is discussed in Sect. 6.1.

Systematic error sources, such as spectroscopic parameters, possible biases in Odin-SMR calibration and ECMWF temperatures, are not captured by the simulations shown in Fig. 7. These errors were examined in Ekström et al. (2007), who obtained a worst case estimate of a $30 \%$ relative error. The systematic error should in practise be lower than 30\%, since this is a worst case estimate and the errors can possible counteract each other.

\subsection{Retrieved ice water content}

Retrievals of upper tropospheric IWC are shown as multi year mean values for four vertical layers in Fig. 8. The retrievals produce effectively no ice inside regions known to have a low degree of high altitude (thick) clouds, such as an area west of South America. This indicates that the retrievals have a low degree of false cloud detections. Regions of highest mean IWC and the highest RHi at $10.5-13.5 \mathrm{~km}$ match quite closely. On the other hand, there is a clear difference 

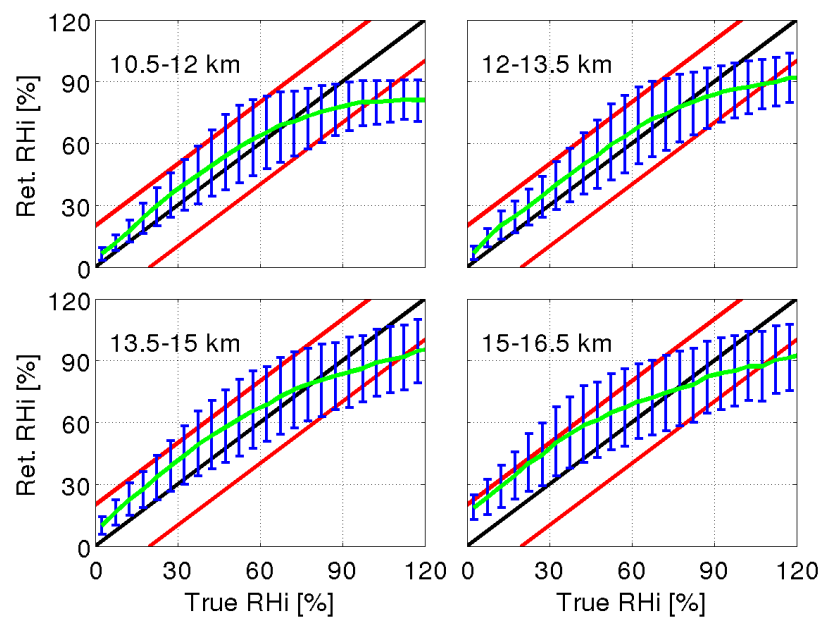

Fig. 7. Statistics for simulated relative humidity retrievals. The green line is the mean retrieved RHi for each interval, the vertical bars show the range between the 14 and $86 \%$ percentiles (corresponds to $\pm 1 \sigma$ ), the black line the one to one line, and the red lines correspond to a $20 \% \mathrm{RHi}$ error.

between Figs. 6 and 8 for the highest altitudes where regions with high RHi are much wider than regions with high IWC, in contrast to the underlying layers. As argued by Ekström and Eriksson (2008), based on CloudSat and Aura-MLS data, this can potentially be explained as even though the dynamics of the uppermost troposphere is partly controlled by zonal mixing, the transport of higher IWC can not be performed over long distances. This as cloud ice particles will evaporate or fall out during the transport. Hence, the IWC throughout the upper troposphere appears to be largely determined by the strength of local convection. That this feature is captured shows that the retrievals can distinguish between RHi and IWC, but it is stressed that completely independent information is not obtained. As for RHi, all horizontal structures are based on measurement information. Significant IWC values are becoming more localised with increasing altitude, a fact showing that the vertical information has been extracted from the measurements.

The IWC retrieval accuracy is shown in Fig. 9. The retrieved IWC compares well to the true IWC for the layer around $14.25 \mathrm{~km}$. Significant systematic errors are found for the other layers, caused by incomplete measurement information in the same manner as for RHi. The general pattern is also the same as for RHi, there is a tendency for overestimation for low IWC and vice versa. For example, the underestimation of high IWC is caused by a combination of two effects: 1. Such cases are less frequent and BMCI puts more weight on the more common situation of a lower IWC. 2. Screening by clouds at higher altitudes. For measurements of thick clouds with large vertical extension, the sensitivity to the lower part of the clouds is small and the retrieval algo-

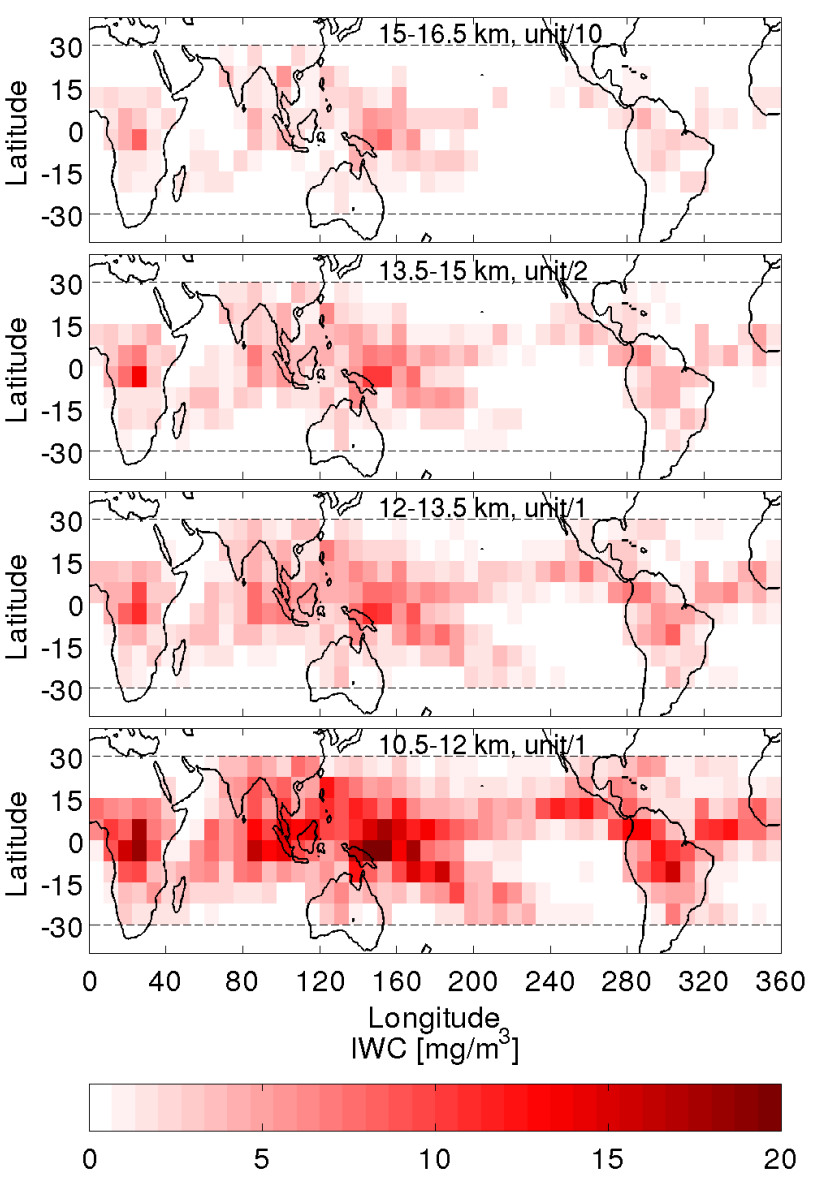

Fig. 8. Odin-SMR multi year means of retrieved ice water content.

rithm will result in some kind of mean IWC at the lowermost levels. Thus, a noticeable difference is that the lowermost layer has the largest retrieval errors for IWC, whereas the uppermost layer has the largest retrieval errors for RHi. The overall IWC precision and accuracy are $\sim 50 \%$.

The retrieval database does not include the full natural variability of microphysical quantities, i.e. deviations from the assumptions regarding the MH97 PSD, refractive index and solid spherical particles. In Eriksson et al. (2007) random and systematic errors associated with these uncertainties are discussed. The random errors in retrieved IWC due to PSD variations was estimated to a $40 \%$ relative error, and the same error for refractive index and shape variations to $15 \%$. By combining these uncertainties, and the ones covered by Fig. 9, and assuming that they are independent from each other, the total precision of Odin-SMR upper tropospheric IWC observations is found to be $\sim 65 \%$.

The assumed MH97 PSD parameterisation and assumed refractive index and solid spherical particles give, possibly also, rise to systematic errors, estimated in Eriksson et al. (2007) to be $30 \%$ and $15 \%$, respectively. Systematic errors associated with absorption spectroscopic parameters 


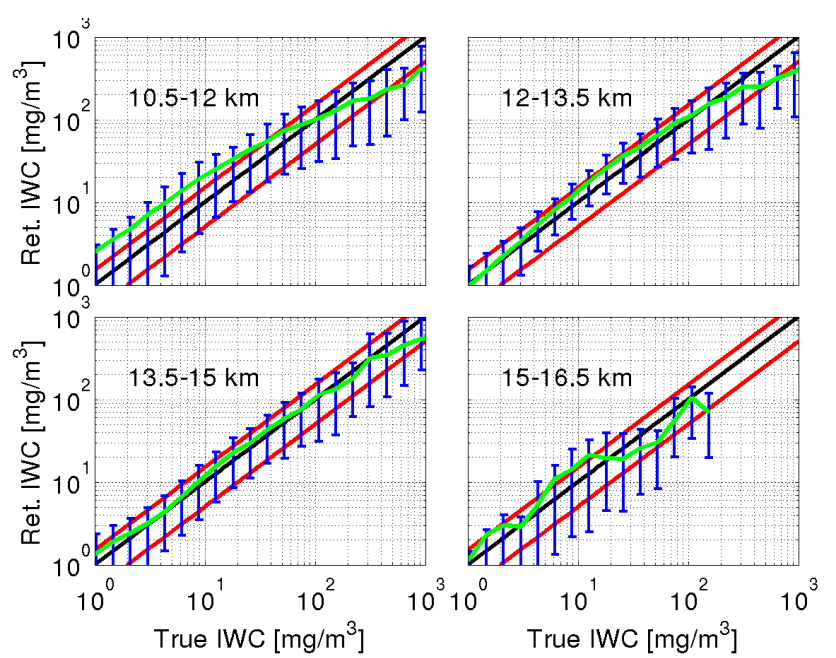

Fig. 9. Statistics for simulated ice water content retrievals. The green line is the mean retrieved ice water content for each interval, the vertical bars show the range between the 14 and $86 \%$ percentiles (corresponds to $\pm 1 \sigma$ ), the black line the one to one line, and the red lines correspond to a $50 \%$ ice water content error.

and Odin-SMR calibration were also considered by Eriksson et al. (2007). These errors are regarded as negligible compared to the other systematic errors. Hence, the combined effect of systematic errors discussed is estimated to be below $50 \%$.

\section{Comparisons}

Retrieved upper tropospheric RHi and IWC are compared to results from AURA-Microwave Limb Sounder (MLS), CloudSat and earlier Odin-SMR retrievals.

\subsection{Relative humidity}

The RHi results (here denoted v2) are compared to results from AURA-MLS (Read et al., 2007, v2.2) and to previous Odin-SMR inversions (Ekström et al., 2007, here denoted v1) in Fig. 10. Odin-SMR and AURA-MLS have approximately the same vertical resolution of $\sim 5 \mathrm{~km}$. AURA-MLS values were interpolated to the Odin-SMR altitudes. OdinSMR v1 RHi results were retrieved for two layers centred around 200 and $130 \mathrm{hPaand}$ are compared to v2 results for the corresponding layers. An averaging over $7.5^{\circ} \times 7.5^{\circ}$ in latitude and longitude is applied in Fig. 10. A main reason for using this relatively broad averaging is to decrease the impact of differences in horizontal weighting that are generated through the uneven latitude sampling of Odin-SMR.

The weighted total least square linear lines in Fig. 10 all have a slope greater than one. That is, the Odin-SMR v2 retrievals span a lower range of RHi than the other two datasets. The main cause to this feature is the influence of a priori
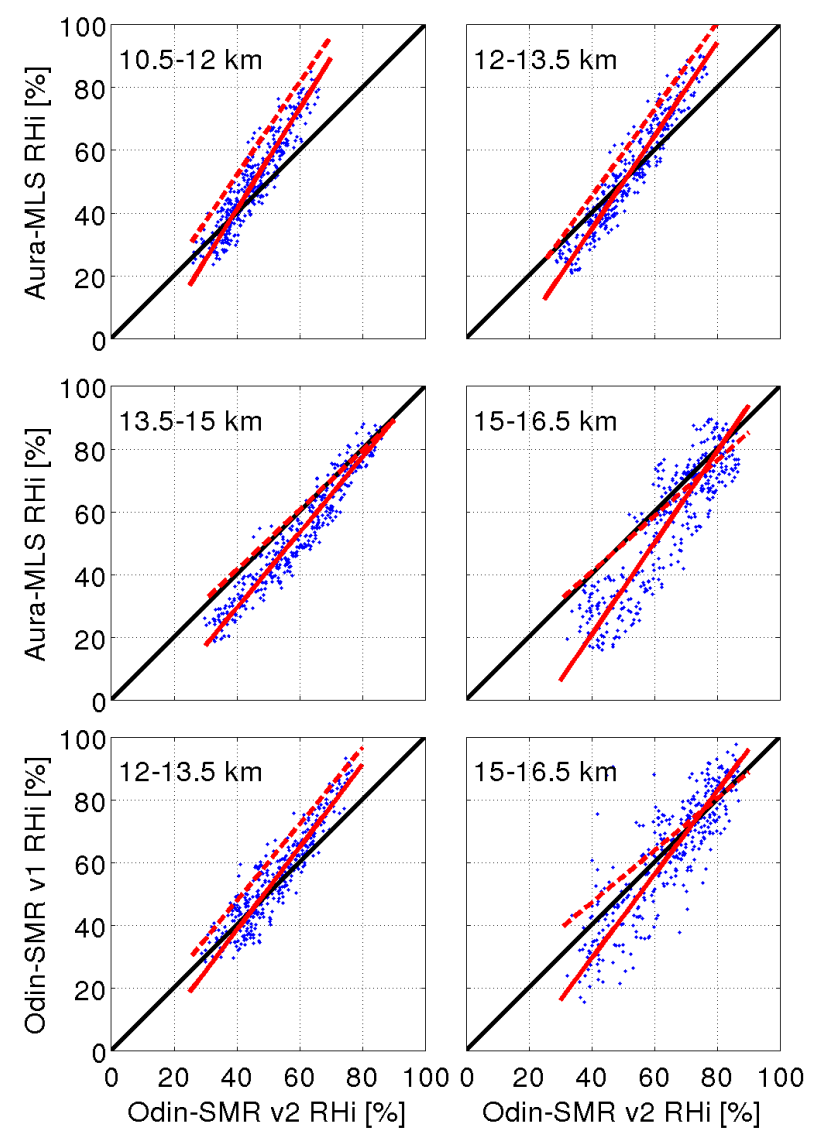

Fig. 10. Comparison of multi year averages of Odin-SMR v2, AURA-MLS v.2.2 and Odin-SMR v1 RHi retrievals. The averages (blue dots) are calculated for areas with an extension $7.5^{\circ}$ in both latitude and longitude. The black line is the one-to-one line, the red line is the weighted total least square fitted line and dashed red line is the weighted total least square fitted line after a correction procedure described in the text.

data (see Fig. 7 and the discussion in Sect. 5.3). The earlier Odin-SMR retrievals were based on simple regression models and were not affected by a priori assumptions in the same manner. As a consequence, the v1 retrievals could yield unrealistically high RHi (including $>200 \% \mathrm{RHi}$ ). In addition, those retrievals were less advanced when it comes to handling the impact of weak clouds that generates an overestimation of RHi. However, multi year average RHi fields are dominated by "clear sky" retrievals. For clear sky measurements the v1 retrievals use a regression model that maps measured radiances to RHi by comparing to simulated measurements with fixed RHi. These retrievals are very noise sensitive, as the measured radiance including measurement noise is directly mapped to RHi. As the relationship between RHi and radiance is not linear, averaged results will be biased high. This as a positive noise will result in an increase in RHi that is greater than the decrease in RHi a negative noise with 
the same magnitude would produce. The v2 retrievals uses a priori data and are less noise sensitive, but on the other hand retrievals are biased towards mean RHi. Thus there are fundamentals differences between the $\mathrm{v} 1$ and $\mathrm{v} 2$ retrieval algorithms. Both versions introduce biases. It is judged that the $v 2$ results give a fairer representation of the actual measurement information found in Odin-SMR spectra.

A significant a priori "contamination" can not be avoided for individual v2 retrievals, but it could be decreased somewhat by introducing a geographical and seasonal varying a priori. This choice was rejected so as to maintain a situation where all horizontal and temporal structures in estimated RHi fields are directly attributable to the measurements. On the other hand, the contamination can be decreased for average values in a relatively straightforward manner. If the humidity inside each grid box were constant, it should be possible to compensate for the a priori influence through Fig. 7 that gives the systematic error for each range of RHi. The dashed (red) line in Fig. 7 is the weighted total least square linear line after such a compensation is applied to the average values displayed. The natural variability is not zero and perfect compensation is not achieved. However, a first order correction for a priori influence should be reached and the dashed lines are used below for further comparisons.

The changes in spectroscopic variables (Sect. 4.2.1) should result in drier Odin-SMR values for v2 compared to v1, and the differences in Fig. 10 (for dashed line) between $\mathrm{v} 1$ and $\mathrm{v} 2$ are primarily caused by these changes. For the $15.0-16.5 \mathrm{~km}$ layer the screening applied to the $544 \mathrm{GHz}$ data in v1 must also be considered. The screening left only spectra with a less frequently used longer integration time $(1.87 \mathrm{~s})$ that gives a less pronounced impact of random calibration errors. The introduction of a priori data made it also possible to handle higher calibration errors and the data included differ between $\mathrm{v} 2$ and $\mathrm{v} 1$. This point explains also the higher scatter between v1 and v2 mean RHi for the $15.0-16.5 \mathrm{~km}$ layer than for $12.0-13.5 \mathrm{~km}$.

The agreement between Odin-SMR and Aura MLS is excellent between 13.5 and $16.5 \mathrm{~km}$ (after correction for a priori influences). The consistency is good also at $10.5-13.5 \mathrm{~km}$ for regions with low RHi.

The highest differences are found for wet regions below $13.5 \mathrm{~km}$ where MLS shows significantly higher values than SMR. The deviation is higher after a priori compensation, but the correction here is questionable. Odin-SMR on average underestimates RHi above 70-75\% (Fig. 7), but such high relative humidities are not found among the v2 average values below $13.5 \mathrm{~km}$ and the correction gives consistently drier data. The part of the data that should have the opposite correction is lost in the averaging and the compensation procedure fails for high humid average conditions. There is a better match between MLS and v1 data for these lower and wetter regions (Ekström et al., 2008). However, the better agreement is probably partly caused in artificial ways by allowing unrealistic values and interference of weak clouds in v1, as discussed above. Figure 12 in Ekström et al. (2008) indicates that the new Odin-SMR retrievals should agree quite well with data from UARS MLS, below $13.5 \mathrm{~km}$. In any case, the Odin-SMR retrievals are for these lower altitudes especially sensitive to the selection of "continuum parameterisation" for $\mathrm{H}_{2} \mathrm{O}$ and $\mathrm{N}_{2}$. Large uncertainties exist around these parameterisations for both species and a change was made for $\mathrm{H}_{2} \mathrm{O}$ (Sect. 4.2.1) in order to use newest available data. Accordingly, some kind of validation for selected parameterisations is needed before any more firm conclusions can be drawn.

\subsection{Ice water content}

The IWC results (here denoted v2) are compared to results from CloudSat (Austin et al., 2009) and to previous OdinSMR results (Eriksson et al., 2007, 2008, here denoted v1). It should be noted that the comparison uses the official CloudSat IWC retrievals (2B-CWC-RO, R04) and not the implicit retrieval made when constructing the retrieval database. The main difference between these two retrieval approaches is assumptions regarding the PSD.

As opposed to RHi retrievals, the Odin-SMR random calibration error does not significantly affect IWC retrievals. This means that not only retrieved mean values can be considered in the comparison. Comparing higher order statistics gives additional information on how the datasets relate. This is of particular interest for tropical upper tropospheric IWC, which exhibits non-Gaussian statistics and covers a large span of values, typically from 0 to $1000 \mathrm{mg} \mathrm{m}^{-3}$. Thus, comparisons of retrieved PDF of upper tropospheric cloud ice are considered.

Figure 11 shows PDFs of retrieved IWC values. Table 1 gives the corresponding overall mean IWC. Since there is a fundamental difference between the observation geometries and resolution of the two sensors, CloudSat data have been averaged in different ways to show the impact of spatial sampling on IWC PDFs. In the case of CloudSat-a, individual IWC profiles have been averaged over the four altitude ranges considered. The sampling volume is accordingly a vertical cylinder with a height of $1.5 \mathrm{~km}$. For CloudSat-b the data are averaged over the same vertical layers, but weighted in the horizontal direction according to Odin-SMR's observation geometry and antenna pattern. Thus, the sampling volume is a tilted cylinder with a $1.5 \mathrm{~km}$ vertical extension. This does not change mean IWC values compared to the CloudSat-a case. The averaging for CloudSat-c aims at producing data that can be directly compared to the Odin-SMR v2 retrievals and the vertical resolution must also be considered. The CloudSat-c PDF is obtained by weighting CloudSat-b data with the ensemble mean averaging kernels in Fig. 5. The Odin-SMR averaging kernels were mainly derived in order to get a rough estimate of the vertical resolution of Odin-SMR. The derived 


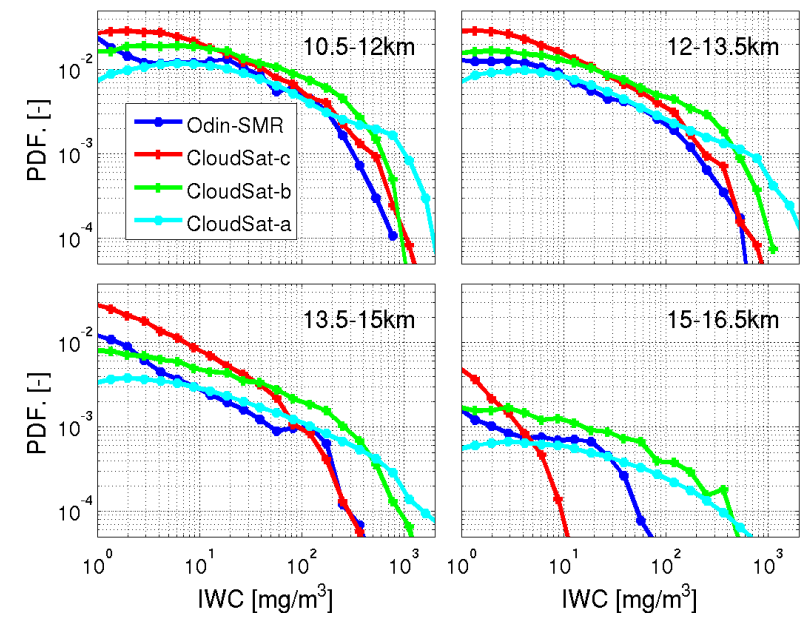

Fig. 11. PDFs of Odin-SMR (blue) and CloudSat (red, green, and cyan) retrieved ice water contents. The different averages (a), (b) and (c) of CloudSat data are described in the text.

averaging kernel matrix is an average over the complete training data ensemble. Hence, applying the kernels on individual CloudSat-b profiles must only be seen as a rough estimate what the Odin-SMR retrieval algorithm would have retrieved. Anyhow, CloudSat-C data are more appropriate than CloudSat-b data to directly compare to Odin-SMR retrievals.

As the kernels were derived for the logarithm of IWC, the same transformation must be applied here. This causes some ambiguity around how to treat CloudSat data with low IWC, and especially the case of IWC $=0$. The detection limit for Odin-SMR is $\approx 1 \mathrm{mg} \mathrm{m}^{-3}$ and all IWC values below this level can be treated as "clear sky" with respect to Odin-SMR measurements. To mimic this, CloudSat data were set to have a minimum value of $1 \mathrm{mg} \mathrm{m}^{-3}$ and final results were compensated in such way that a constant IWC field of $1 \mathrm{mg} \mathrm{m}^{-3}$ gives a CloudSat-c value of 0 . That is, the averaging kernel matrix was multiplied both with each "real" profile (with minimum values of $1 \mathrm{mg} \mathrm{m}^{-3}$ ) and with a profile, where all values are $1 \mathrm{mg} \mathrm{m}^{-3}$ and the latter resulting profile is subtracted from the former.

A spatial averaging has a clear influence on the PDF (Fig. 11). The impact is especially clear for highest IWC as such values are normally confined to small volumes and are less frequent for averages covering larger volumes. The opposite occurs for low IWC, where the PDFs increase with spatial averaging.

Between 10.5 and $15 \mathrm{~km}$, the Odin-SMR PDFs coincides well with the CloudSat-c ones for high IWC, but is consistently below for lower IWC. This can not be explained by influence of a priori as the $\mathrm{v} 2$ retrievals tend to give an overestimation for lower IWC (Fig. 9). As noted above, the OdinSMR and CloudSat retrievals are based on different assump-
Table 1. Retrieved ice water content mean values. The different averages ( $a, b$ and $c$ ) of CloudSat data are described in the text. All values in $\mathrm{mg} \mathrm{m}^{-3}$.

\begin{tabular}{lcccc}
\hline & $10.5-12 \mathrm{~km}$ & $12-13.5 \mathrm{~km}$ & $13.5-15 \mathrm{~km}$ & $15-16.5 \mathrm{~km}$ \\
\hline CloudSat-a & 8.4 & 5.1 & 2.1 & 0.41 \\
CloudSat-b & 8.4 & 5.1 & 2.1 & 0.41 \\
CloudSat-c & 6.1 & 3.5 & 1.3 & 0.055 \\
Odin-SMR & 4.4 & 2.1 & 0.76 & 0.085 \\
\hline
\end{tabular}

tions on the PSD. Eriksson et al. (2008) inverted one month of CloudSat observations using MH97 (the PSD applied for Odin-SMR) and compared to official (R04) results. A pattern resembling the one noted above was found: good agreement for high IWC but lower PDF with MH97 for lower IWC. The average values when using MH97 are 10, 25 and 41\% below official data at $11.0,12.0$ and $14.0 \mathrm{~km}$, respectively. The differences between v2 and CloudSat-c are (Table 1) 28, 40 and $42 \%$ for the $11.25,12.75$ and $14.25 \mathrm{~km}$ layers, respectively. Accordingly, for $10.5-15.0 \mathrm{~km}$, there should be relatively small deviations between Odin-SMR v2 data and CloudSat inversions assuming MH97 as PSD.

The situation is different for $15.0-16.5 \mathrm{~km}$, where the Odin-SMR average is $55 \%$ above CloudSat. The PDFs obtained by Eriksson et al. (2008) for $15.5 \mathrm{~km}$ indicate that the deviation between v2 and CloudSat retrievals should increase with a switch to MH97. The difference can instead potentially be explained by the fact that the two sensors perform measurements at different local times and high altitude clouds have a clear diurnal cycle. It might be that Odin-SMR measures the clouds at a later stage in their life where convective updrafts have brought up more ice particles to higher altitudes.

Figure 12 shows the PDF of retrieved pIWP for Odin-SMR v1 and v2. pIWP is defined in Eriksson et al. (2007) and corresponds roughly to the column ice mass above $12 \mathrm{~km}$. The retrieved profiles from $v 2$ have been weighted with the averaging kernel provided by Eriksson et al. (2007). The main limitation of the $\mathrm{v} 1$ retrievals was that homogeneous cloud layers were assumed and a simple scheme to correct for this shortcoming was introduced. Cloud inhomogeneity effects are handled in detail by the 22 inversions and the good agreement between $\mathrm{v} 2$ and $\mathrm{v} 1 \mathrm{~b}$ PDFs confirms that the correction applied on v1 data was justified.

\section{Conclusions}

A Bayesian retrieval algorithm has been developed and applied to Odin-SMR measurements of tropical upper tropospheric humidity and cloud ice. The core of the algorithm is the generation of a retrieval database, consisting of atmospheric states and corresponding synthetic measurements. Great care must be taken to create atmospheric states that 
mimic real conditions in detail. This is here achieved by merging data from several sources, with CloudSat radar measurements as the cornerstone. The generated atmospheric states together with sensor characteristics are fed into a state-of-the-art radiative transfer model to simulate synthetic measurements. The main advantage of this methodology is that the basic information content from radar measurements is preserved, at the same time as atmospheric quantities are given realistic variability, and a database closely matching observed brightness temperatures could be created (Fig. 3).

Odin-SMR retrievals of tropospheric relative humidity (RHi) and cloud ice mass were introduced by Ekström et al. (2007) and Eriksson et al. (2007). Cloud inhomogeneities inside the sampled volume was reported as a major cloud ice mass retrieval uncertainty. It was found that assuming homogeneous cloud layers will lead to a systematic underestimation of cloud ice mass. The main achievement of this work is that cloud structure inhomogeneity effects are now handled in a near optimal manner, by using high resolution (compared to Odin-SMR) radar data as input for the generation of atmospheric states in the retrieval database. Only a marginal systematic error should remain and estimation of the corresponding random error is an integrated part of the inversions.

Another major improvement is that simultaneous profile retrievals of RHi and ice water content (IWC) can now be performed compared to the earlier retrievals where cloud ice mass and RHi were treated separately. Further, the earlier cloud ice mass retrieval product was limited to the column integrated mass above $\sim 12 \mathrm{~km}$, and RHi was retrieved only for two layers centred around 200 and $130 \mathrm{hPa}$. Additionally, the introduction of a priori data made it possible to also handle a higher level of calibration error found in data of the Odin-SMR $544 \mathrm{GHz}$ channel (level 1b v6), enabling the use of all data for RHi retrievals.

It was determined that Odin-SMR can measure tropical upper tropospheric profiles of RHi and IWC with a vertical resolution of $\sim 5 \mathrm{~km}$. The best retrieval performance is found between 11 and $15 \mathrm{~km}$ in altitude. The retrieval precision is $<20 \%$ RHi and $<65 \%$ and systematic errors are below $30 \%$ and $50 \%$, for RHi and IWC, respectively. Greatly improved confidence and precision in the RHi retrievals has been achieved. This, at the cost of a clear a priori influence in results, which is strongest for high RHi due to a saturation effect in measurement signal. The a priori "contamination" must be considered in comparing to other datasets and a simple correction procedure for a priori influence was suggested. Eriksson et al. (2007) estimated the deviations between local average RHi values for Aura MLS and earlier Odin-SMR retrievals to be $\leq 10 \%$ RHi. This general accuracy estimate is retained, but this comparison indicates an even better agreement in the $13.5-16.5 \mathrm{~km}$ altitude range. The highest deviations (10-15\% RHi) are found for lower altitudes (10-13 km) and most humid conditions. The new retrievals are closer to

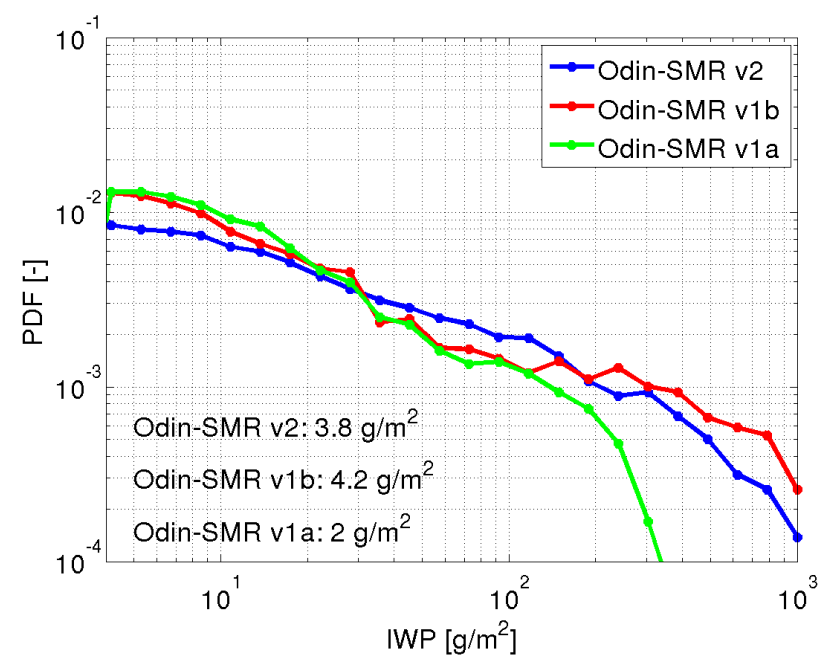

Fig. 12. New Odin-SMR (v2) and previous Odin-SMR (v1) retrieved pIWP. For v1 the PDF of both original data (v1a) and after a correction for cloud inhomogeneity effects (v1b).

UARS MLS results. However, for these lower altitudes the Odin-SMR retrievals are especially sensitive to the selection of "continua parameterisation" for $\mathrm{H}_{2} \mathrm{O}$ and $\mathrm{N}_{2}$, where large uncertainties exist for both species, and a more detailed analysis is needed before any conclusions can be drawn.

Limited knowledge of both average and local particle size distributions (PSD) is a main issue for all remote sensing of cloud ice mass. This work provides no progress on this point. The Odin-SMR retrievals are based on the assumption that the PSD parameterisation derived by McFarquhar and Heymsfield (1997) (hereafter MH97) is the best representation of the mean PSD in the tropical region. In lack of relevant data, no attempt to include PSD variations in the database was made and the related errors have to be estimated separately (here taken from Eriksson et al., 2007). It is stressed that no large systematic retrieval errors are introduced as long as MH97 is a fair representation of the mean PSD, and this retrieval error should primarily be of random nature.

Odin-SMR and (official) CloudSat IWC retrievals show clear deviations, where the differences between mean values are -40 to $+55 \%$. Based on earlier studies where CloudSat observations were inverted with the same PSD as applied for Odin-SMR (MH97), it was judged that differences below $15 \mathrm{~km}$ in both average and distribution of IWC retrieved largely can be explained by different PSD assumptions. Diurnal variations are suggested as the main cause to the disagreement above $15 \mathrm{~km}$, and have probably also an impact at lower altitudes.

Dedicated $\mathrm{mm}$ and sub-mm down-looking instruments for cloud observations have been suggested (Evans and Stephens, 1995; Buehler et al., 2007) and the results here 
serve as a practical demonstration of the potential of those instrument concepts. This is the case as, for the observations considered, Odin-SMR shares the basic properties of the measurement principle used. Odin-SMR is in this context a simple instrument and a greatly limited performance compared to a dedicated instrument is expected, but it is clearly demonstrated that differences in gaseous absorption provides cloud altitude information. This work also shows that satellite cloud radars are important in an indirect manner, the data can be used to improve retrievals from existing/future passive measurements.

The retrieval method could in principle be applied to any passive microwave cloud observations, but the following properties of the CloudSat $94 \mathrm{GHz}$ radar should be noted. The thinnest clouds are not detected by the radar. Further, CloudSat is in a sun-synchronous orbit and this has the consequence that the atmospheric states in a retrieval database do not fully mimic the diurnal variability of clouds. In general, over tropical land maximum cloudiness occur in afternoon, while over oceans the peak is in the early morning. However, the phase of the diurnal cycle may vary from region to region, meaning that the retrieval database to some extent covers diurnal variability. If it is desired to better capture diurnal differences, input from ground-based cloud profiling radars can be used instead, at the expensive of global coverage. The EarthCARE mission (Ingmann, 2004), with launch planned for 2013, will also be in a sun-synchronous orbit, but will provide a better sensitivity to thin clouds.

Acknowledgements. This work has been funded by the Swedish National Graduate School of Space Technology, Luleå Technical University and the Swedish National Space Board. We thank the ARTS community, and particularly Cory Davis who implemented the Monte Carlo module that we have used to simulate radiative transfer in clouds.

Edited by: B. Mayer

\section{References}

Austin, R. T., Heymsfield, A. J., and Stephens, G. L.: Retrieval of ice cloud microphysical parameters using the CloudSat millimeter-wave radar and temperature, J. Geophys. Res., 114, D00A23, doi:10.1029/2008JD010049, 2009.

Boissoles, J., Boulet, C., Tipping, R. H., Brown, A., and Ma, Q.: Theoretical calculation of the translation-rotation collisioninduced absorption in $\mathrm{N}_{2}-\mathrm{N}_{2}, \mathrm{O}_{2}-\mathrm{O}_{2}$, and $\mathrm{N}_{2}-\mathrm{O}_{2}$ pairs, J. Quant. Spectrosc. Radiat. Transfer, 82, 505-516, doi:10.1016/ S0022-4073(03)00174-2, 2003.

Buehler, S. A., Eriksson, P., Kuhn, T., von Engeln, A., and Verdes, C.: ARTS, the Atmospheric Radiative Transfer Simulator, J. Quant. Spectrosc. Radiat. Transfer, 91, 65-93, doi:10.1016/j. jqsrt.2004.05.051, 2005.

Buehler, S. A., Jimenez, C., Evans, K. F., Eriksson, P., Rydberg, B., Heymsfield, A. J., Stubenrauch, C., Lohmann, U., Emde, C., John, V. O., Sreerekha, T. R., and Davis, C. P.: A concept for a satellite mission to measure cloud ice water path and ice particle size, Q. J. Roy. Meteor. Soc., 133, 109-128, doi:10.1002/qj.143, 2007.

Davis, C., Emde, C., and Harwood, R.: A 3D polarized reversed Monte Carlo radiative transfer model for $\mathrm{mm}$ and sub-mm passive remote sensing in cloudy atmospheres, IEEE Trans. Geosci. Remote Sensing, 43, 1096-1101, 2005.

Davis, C. P., Evans, K. F., Buehler, S. A., Wu, D. L., and Pumphrey, H. C.: 3-D polarised simulations of space-borne passive $\mathrm{mm} / \mathrm{sub}$ mm midlatitude cirrus observations: a case study, Atmos. Chem. Phys., 7, 4149-4158, 2007, http://www.atmos-chem-phys.net/7/4149/2007/.

Ekström, M., Eriksson, P., Rydberg, B., and Murtagh, D. P.: First Odin sub-mm retrievals in the tropical upper troposphere: humidity and cloud ice signals, Atmos. Chem. Phys., 7, 459-469, 2007 , http://www.atmos-chem-phys.net/7/459/2007/.

Ekström, M., Eriksson, P., Read, W. G., Milz, M., and Murtagh, D. P.: Comparison of satellite limb-sounding humidity climatologies of the uppermost tropical troposphere, Atmos. Chem. Phys., 8, 309-320, 2008,

http://www.atmos-chem-phys.net/8/309/2008/.

Ekström, M. and Eriksson, P.: Altitude resolved ice-fraction in the uppermost tropical troposphere, Geophys. Res. Lett., 35, L13822, doi:10.1029/2008GL034305, 2008.

Emde, C., Buehler, S. A., Davis, C., Eriksson, P., Sreerekha, T. R., and Teichmann, C.: A polarized discrete ordinate scattering model for simulations of limb and nadir longwave measurements in 1D/3D spherical atmospheres, J. Geophys. Res., 109(D24), D24207, doi:10.1029/2004JD005140, 2004.

Eriksson, P., Ekström, M., Rydberg, B., and Murtagh, D. P.: First Odin sub-mm retrievals in the tropical upper troposphere: ice cloud properties, Atmos. Chem. Phys., 7, 471-483, 2007, http://www.atmos-chem-phys.net/7/471/2007/.

Eriksson, P., Ekström, M., Rydberg, B., Wu, D. L., Austin, R. T., and Murtagh, D. P.: Comparison between early Odin-SMR, Aura MLS and CloudSat retrievals of cloud ice mass in the upper tropical troposphere, Atmos. Chem. Phys., 8, 1937-1948, 2008, http://www.atmos-chem-phys.net/8/1937/2008/.

Evans, K. F. and Stephens, G. L.: Microwave Radiative Transfer through Clouds Composed of Realistically Shaped Ice Crystals. Part II. Remote Sensing of Ice Clouds, J. Atmos. Sci., 52, 20582072, 1995.

Evans, K. F., Walter, S. J., Heymsfield, A. J., and Deeter, M. N.: Modelling of submillimeter passive remote sensing of cirrus clouds, J. Appl. Meteor., 37, 184-205, 1998.

Evans, K. F., Walter, S. J., Heymsfield, A. J., and McFarquhar, G. M.: Submillimeter-wave cloud ice radiometer: Simulations of retrieval algorithm performance, J. Geophys. Res., 107, 2.12.21, 2002.

Evans, K. F., Racette, J. R. W. P. E., Heymsfield, G., and Li, L.: Ice cloud retrievals and analysis with the Compact Scanning Submillimeter Imaging Radiometer and the Cloud Radar System during CRYSTAL FACE, J. Appl. Meteor., 44, 839-859, 2005.

Golubiatnikov, G. Y., Koshelev, M., and Krupnov, A. F.: Pressure shift and broadening of $1_{10}-1_{01}$ water vapor lines by atmosphere gases, J. Quant. Spectrosc. Radiat. Transfer, 109, 1828-1833, 2008.

Ingmann, P.: EarthCARE -Earth Clouds, Aerosols and Radiation Explorer, in: Reports for mission selection, the six candidate 
Earth explorer missions, ESA SP-1279, ESA Publications Division c/o ESTEC, Noordwijk, The Netherlands, 2004.

Jimenez, C., Eriksson, P., and Murtagh, D.: First inversions of observed sub-millimetre limb sounding radiances by neural networks, J. Geophys. Res., 108(D24), 4791, doi:10.1029/ 2005GL022681, 2003.

John, V. O. and Soden, B. J.: Does convectively-detrained air cloud ice enhance water vapor feedback?, Geophys. Res. Lett., 33, D20701, doi:10.1029/2006GL027620, 2006.

Kummerow, C.: Beamfilling errors in passive microwave rainfall retrievals, J. Appl. Meteor., 37, 356-370, 1998.

Liebe, H. J., Hufford, G. A., and Cotton, M. G.: Propagation modeling of moist air and suspended water/ice particles at frequencies below $1000 \mathrm{GHz}$, in: AGARD 52nd Specialists' Meeting of the Electromagnetic Wave Propagation Panel, Palma de Mallorca, Spain, 3-1-3-10, ftp://ftp.its.bldrdoc.gov/pub/mpm93/, 1993.

Liu, C. and Zipser, E. J.: Diurnal cycles of precipitation, clouds, and lightning in the tropics from 9 years of TRMM observations, Geophys. Res. Lett., 35, L04819, doi:10.1029/2007GL032437, 2008.

McFarlane, S. A., Evans, K. F., and Ackerman, A. S.: A Bayesian algorithm for the retrieval of liquid water cloud properties from microwave radiometer and millimeter radar data, J. Geophys. Res., 107(D16), 4317, doi:10.1029/2001JD001011, 2002.

McFarquhar, G. M. and Heymsfield, A. J.: Parameterization of tropical cirrus ice crystal size distribution and implications for radiative transfer: Results from CEPEX, J. Atmos. Sci., 54, 21872200, 1997.

Murtagh, D., Frisk, U., Merino, F., Ridal, M., Jonsson, A., Stegman, J., Witt, G., Eriksson, P., Jiménez, C., Megie, G., de La Noë, J., Ricaud, P., Baron, P., Pardo, J. R., Hauchcorne, A., Llewellyn, E. J., Degenstein, D. A., Gattinger, R. L., Lloyd, N. D., Evans, W. F. J., McDade, I. C., Haley, C., Sioris, C., von Savigny, C., Solheim, B. H., McConnell, J. C., Strong, K., Richardson, E. H., Leppelmeier, G. W., Kyrölä, E., Auvinen, H., and Oikarinen, L.: An overview of the Odin atmospheric mission, Can. J. Phys., 80, 309-319, 2002.

Podobedov, V. B., Plusquellic, D. F., Siegrist, K. E., Frasera, G. T., Ma, Q., and Tipping, R. H.: New measurements of the water vapor continuum in the region from 0.3 to $2.7 \mathrm{THz}$, J. Quant. Spectrosc. Radiat. Transfer, 109, 458-467, 2008.

Read, W. G., Lambert, A., Bacmeister, J., Cofield, R. E., Christensen, L. E., Cuddy, D. T., Daffer, W. H., Drouin, B. J., Fetzer, E., Froidevaux, L., Fuller, R., Herman, R., Jarnot, R. F., Jiang, J. H., Jiang, Y. B., Kelly, K., Knosp, B. W., Kovalenko, L. J., Livesey, N. J., Liu, H.-C., Manney, G. L., Pickett, H. M., Pumphrey, H. C., Rosenlof, K. H., Sabounchi, X., Santee, M. L., Schwartz, M. J., Snyder, W. V., Stek, P. C., Su, H., Takacs, L. L., Thurstans, R. P., Vömel, H., Wagner, P. A., Waters, J. W., Webster, C. R., Weinstock, E. M., and Wu, D. L.: Aura Microwave Limb Sounder upper tropospheric and lower stratospheric $\mathrm{H}_{2} \mathrm{O}$ and relative humidity with respect to ice validation, J. Geophys. Res., 112, D24S35, doi:doi:10.1029/2007JD008752, 2007.
Rodgers, C. D.: Optimal linear inverse methods, in: Inverse methods for atmospheric sounding: Theory and practise, World Scientific Publishing Co. Pte. Ltd, Singapore, 65-80, 2000.

Rydberg, B., Eriksson, P., and Buehler, S. A.: Prediction of cloud ice signatures in submillimetre emission spectra by means of ground-based radar and in situ microphysical data, Q. J. Roy. Meteor. Soc., 133, 151-162, 2007.

Seo, E. K. and Liu, G.: Retrievals of cloud ice water path by combining ground cloud radar and satellite high-frequency microwave measurements near the ARM SGP site, J. Geophys. Res., 110, D14203, doi:10.1029/2004JD005727, 2005.

Stephens, G. L., Vane, D. G., Boain, R. J., Mace, G. G., Sassen, K., Wang, Z. E., Illingworth, A. J., O'Connor, E. J., Rossow, W. B., Durden, S. L., Miller, S., Austin, R. T., Benedetti, A., and Mitrescu, C.: The CloudSat mission and the A-train - A new dimension of space-based observations of clouds and precipitation, B. Am. Meteorol. Soc., 83, 1771-1790, 2002.

Tamminen, J. and Kyrölä, E.: Bayesian solution for nonlinear and non-Gaussian inverse problems by Markov chain Monte Carlo method, J. Geophys. Res., 106, 14377-14390, 2001.

Urban, J., Lautié, N., Le Flochmoën, E., Jiménez, C., Eriksson, P., Dupuy, E., El Amraoui, L., Ekström, M., Frisk, U., Murtagh, D., de La Noë, J., Olberg, M., and Ricaud, P.: Odin/SMR limb observations of stratospheric trace gases: Level 2 processing of $\mathrm{ClO}, \mathrm{N}_{2} \mathrm{O}, \mathrm{O}_{3}$, and $\mathrm{HNO}_{3}$, J. Geophys. Res., 110, D14307, doi: 10.1029/2004JD005741, 2005.

Venema, V., Ament, F., and Simmer, C.: A Stochastic Iterative Amplitude Adjusted Fourier Transform algorithm with improved accuracy, Nonlin. Processes Geophys., 13, 321-328, 2006, http://www.nonlin-processes-geophys.net/13/321/2006/.

Waters, J. W., Froidevaux, L., Harwood, R. S., Jarnot, R. F., Pickett, H. M., Read, W., Siegel, P. H., Cofield, R. E., Filipiak, M. J., Flower, D. A., Holden, J. R., Lau, G. K., Livesey, N. J., Manney, G. L., Pumphrey, H. C., Santee, M. L., Wu, W. L., Cuddy, D. T., Lay, R. R., Loo, M. S., Perun, V. S., Schwartz, M. J., Stek, P., Thurstans, R. P., Boyles, M. A., Chandra, K. M., Chavez, M. C., Chen, G. S., Chudasama, B. V., Dodge, R., Fuller, R. A., Girard, M. A., Jiang, J. H., Jiang, Y. B., Knosp, B. W., LaBelle, R., Lam, J. C., Lee, K. A., Miller, D., Oswald, J. E., Patel, N. C., Pukala, D. M., Quintero, O., Scaff, D. M., Snyder, W. V., Tope, M. C., Wagner, P., and Walch, M.: The Earth Observing System Microwave Limb Sounder (EOS MLS) on the Aura satellite, IEEE Trans. Geosci. Remote Sensing, 44, 1075-1092, 2006.

Wu, D. L., Jiang, J. H., and Davis, C. P.: EOS MLS cloud ice measurements and cloudy-sky radiative transfer model, IEEE Trans. Geosci. Remote Sensing, 44, 1156-1165, 2006.

Zinner, T., Marshak, A., Lang, S., Martins, J. V., and Mayer, B.: Remote sensing of cloud sides of deep convection: towards a three-dimensional retrieval of cloud particle size profiles, Atmos. Chem. Phys., 8, 4741-4757, 2008, http://www.atmos-chem-phys.net/8/4741/2008/. 